\title{
Os arquivos empresariais em Portugal: do tradicional ao cloud computing
}

António Muñoz Cañavate

\begin{abstract}
Professor no Departamento de Informação e Documentação, Universidade de Extremadura. Espanha. Doutor em Documentação, Universidade de Granada.Especialista em Gestão da Informação Empresarial e Inteligência Competitiva.
\end{abstract}

Maria Gracinda Barata Monteiro

Gerente de empresa, Monteiro \& PaisConsultores, LDA. Licenciada em Organização e Gestão de Empresas, Instituto Superior de Ciências do Trabalho e da Empresa de Lisboa (ISCTE, Portugal)

Maria Cristina Vieira de Freitas

Professora Auxiliar Convidada na Faculdade de Letras, Universidade de Coimbra, Portugal. Doutora em Biblioteconomia e Documentação, Universidade de Salamanca, Espanha. Mestre em Ciência da Informação, Escola de Ciência da Informação, Universidade Federal de Minas Gerais.

Maria Manuel Borges

Professora Auxiliar na Faculdade de Letras, Universidade de Coimbra, Portugal. Doutora em Ciência da Informação, Universidade de Coimbra, na especialidade de Tecnologias de Informação.

http://dx.doi.org/10.1590/1981-5344/3189

As empresas têm o dever de salvaguardar os documentos e de gerir a memória organizacional. O desempenho desse papel depende do grau de sensibilidade e de registro de atividades. Neste estudo, refletimos sobre iniciativas internacionais de preservação dos arquivos de empresa, incidindo no caso português, e finalizamos com tendências no uso das tecnologias nestas organizações. Nesse intento, realizamos uma revisão bibliográfica de textos científicos e consultamos uma dezena de diplomas, 
contrastando os dados obtidos. Os resultados e as conclusões revelam uma tendência para a replicação de modelos e o caráter precoce, intermédio ou tardio das iniciativas internacionais, desencadeadas pelas empresas ou por parcerias com instituições públicas, destacando-se arquivos e universidades. Primeiramente, o foco esteve na proteção e na valorização do património, acrescentando-se, mais recentemente, objetivos tais como a organização e o acesso à informação. As iniciativas nacionais não fogem à regra, notando-se alguma novidade na quantidade e na qualidade das matérias legisladas, sem incidências, nos diplomas, em medidas concretas de preservação da informação digital. No uso das tecnologias, as iniciativas de modernização associam-se à Administração Pública e à assimilação de processos derivados dos ambientes eletrônicos. A comparação com outros países europeus revela um uso pouco intensivo dos serviços na nuvem.

Palavras-chave: Arquivos empresariais; Tecnologias de informação; Administração Pública portuguesa; Portugal; Computação em Nuvem.

\section{Busines archives in Portugal: from the traditional to the cloud computing}

Companies have a duty to safeguard the records of their activities and manage organizational memory. The performance of this role depends on the degree of sensitivity and registration activities. In this study, we reflect on international initiatives regarding the preservation of business records, focusing on the Portuguese case, ending up with trends in the use of technology in these organizations. For this purpose, we did a literature review, including Portuguese legislation. The results and findings reveal a trend for the replication of international models, and the early character, intermediate or late international initiatives, triggered by companies, with or without partnerships with public institutions, mainly archives and universities. On an initial stage the focus was on the protection and enhancement of heritage, but more recently other goals were added 
such as organization and access to information. National initiatives are no exception, noting some novelty in the quantity and quality of legislated materials without impact on concrete strategies to preserve digital information. The use of technology and modernization initiatives are associated with Public Administration and assimilation processes derivatives of electronic environments. The comparison with other European countries reveals a less intensive use of cloud services.

Keywords: Business archives; Information technology; Portuguese Public Administration; Portugal; Cloud computing.

Recebido em 13.06.2017 Aceito em 11.09.2017

\section{Introdução}

A empresa moderna, herdeira da Revolução Industrial, é uma invenção do século XIX. No decorrer do século seguinte, estas organizações passariam a ajustar-se a leis, normas e regulamentos vários e a balizar-se pelo desenvolvimento do escritório como um espaço físico encarregado dos serviços de informação e de administração. Tal fato, acabaria por produzir a separação entre os locais dedicados à administração dos negócios e à produção. É neste contexto que surge um ambiente consagrado à criação, recepção, organização e ordenação dos documentos, ao lado de um outro, o arquivo, tradicionalmente orientado a preservar somente aqueles que serviriam como garantia dos direitos e das obrigações das empresas e dos seus funcionários e clientes (GONZÁLEZ PEDRAZA, 2010a, p. 104-107). Diante de tais condicionantes, as ações de preservação dos arquivos empresariais passariam a direcionar-se, por um lado, para a salvaguarda da memória do território em que os mesmos se encontravam localizados e, por outro, para as evidências históricas das suas atividades econômicas, técnicas e industriais, sendo estas as fontes de informação imprescindíveis para o seu bom conhecimento e estudo.

Os arquivos empresariais, dependendo da sua titularidade - se públicos ou privados - e dos fatores condicionantes que daí derivam, especialmente os de ordem jurídico-legal, são preservados de diversas formas e em distintos locais. Assim, podem ser as próprias empresas a mantê-los ou, contrariamente, a delegar esta tarefa a terceiros, em regime de outsourcing (ou terceirização de serviços), ou, ainda, obedecendo-se a alguma política ou imperativo legal, propiciar o seu ingresso em instituições públicas vocacionadas para o fim, de que são exemplos os centros de documentação e os tradicionais arquivos 
históricos (GONZÁLEZ PEDRAZA, 2010b, p. 31-57). Nestes locais, os fundos documentais de empresas, existentes ou extintas, são mantidos, após um processo de aquisição que pode ocorrer de diversas formas, entre as quais as usualmente referidas são: compra, doação, dação, recolhimento, legado, incorporação, reintegração e depósito (INSTITUTO PORTUGUÊS DA QUALIDADE - IPQ, 2005; BRASIL, 2005).

Tendo em conta ditas variáveis, este artigo providencia uma revisão bibliográfica e documental, de caráter seletivo, sobre os arquivos empresariais, com o objetivo investigar a sua evolução e de identificar as principais iniciativas empreendidas, ao longo do século $X X$ e até ao presente, de modo a traçar uma cartografia compreensiva do problema, para, se possível, refletir sobre o estado da arte nessa matéria, especialmente no que toca ao caso português.

Dado o fato de a bibliografia e de a legislação sobre o assunto se encontrarem dispersas, foram consultados alguns estudos e dispositivos legais considerados exemplares, de modo a apoiar as análises e as reflexões. De igual modo, foram também identificados outros tipos de iniciativas com uma maior expressão em território português. Finalmente, com o intuito de prognosticar algum percurso para essas instituições, à luz de condicionalismos mais recentes, selecionamos algumas das principais tendências que configuram novas formas de lidar com a documentação nos atuais contextos empresariais, após o embate dos arquivos, e das empresas, com as novas tecnologias e, consequentemente, com os formatos digitais, arrematando as análises com uma síntese das principais conclusões obtidas.

\section{Os arquivos empresariais: iniciativas internacionais}

Vários são os estudos dedicados ao mapeamento de iniciativas de relevo, no tocante à organização e à preservação e, mais recentemente, ao acesso à documentação proveniente dos arquivos empresariais. De acordo com Tortella Casares $^{1}$ (2003 apud CORAIOLA, 2012, p. 255), muitas destas iniciativas localizam-se na Europa, no decorrer do século XX. Na sua análise, são citados países que se destacam pelo caráter precoce (Alemanha, Suíça e Holanda), intermédio (Estados Unidos, França e Inglaterra) ou tardio (Itália e Espanha), no capítulo das experiências desenvolvidas nesse âmbito. Quanto às particularidades destas iniciativas, são também referidas aquelas que se apoiam em ações solitárias, desencadeadas pelas próprias empresas ou, contrariamente, em atuações concertadas com instituições privilegiadas pelo papel que desempenham, como os arquivos públicos.

\footnotetext{
1 TORTELLA CASARES, T. Los archivos empresariales: su organización, conservación y uso. In: ERRO, C. Historia empresarial: pasado, presente y retos de futuro. Barcelona: Ariel, 2003. p. 135-152.
} 
Nos seus respetivos estudos, Nuñez Fernandes (2000) e González Pedraza (2010b) defendem que estas primeiras iniciativas europeias, que remontam ao início do século $\mathrm{XX}$, em muito se devem à importância atribuída a estes arquivos como fontes para a história social, econômica e industrial do continente. Neste sentido, elencam um conjunto de exemplos típicos que a nosso ver reforçam estas constatações.

Assim, e começando pela Alemanha, onde segundo esses autores (NUÑEZ FERNÁNDEZ, 2000; GONZÁLEZ PEDRAZA, 2010b) destacam-se companhias como a Krupp, a Siemens e a Bayer, ao instituir arquivos centrais destinados à guarda dos seus documentos ou as chamadas câmaras de comércio, ao organizar arquivos vocacionados à proteção quer dos próprios fundos, quer dos fundos das empresas localizadas no seu raio de ação, citando-se como exemplos: a câmara de comércio da cidade de Colônia, criada em 1906 e o arquivo histórico Rheinisch-Wetfalischer Wirtschaftarchiv, responsável pela custódia dos fundos da região da Renânia-Vestfália. O próprio governo alemão terá também tido um papel importante, ao disponibilizar um comitê encarregado de assessorar as empresas em matéria de organização e de preservação dos seus fundos históricos.

Em outros países, segundo analisa Nuñez Fernández (2000), também se verificam iniciativas que vão no mesmo sentido. É o caso da Suíça, com a fundação, em 1910, na Basiléia, de um arquivo (o Schweizerischen Wirtschaftarchiv) devotado a recolher a documentação das sociedades comerciais, com data de recolhimento retroativa ao século XVIII; ou da Holanda, que desencadeia o processo de criação, em 1914, do Royal Dutch Shelle e, em 1935, do Instituto Nacional de História Social, em ambos os casos com o objetivo de recuperar os fundos dedicados à história social, econômica e comercial do país. Além disso, no Reino Unido, segundo mesmo Nuñez Fernández (2000), e também González Pedraza (2010b), são criados, em 1934, os Business Archives Councils, inicialmente instituições privadas voltadas para preservação dos arquivos empresariais, e que darão origem, mais tarde, ao Council for the Preservation of Business Archives e ao National Register of Archives, destinados, respectivamente, a recolher e a recensear os arquivos históricos de empresas do país. Segundo o autor, em 1985, foram publicados, por esta instituição, dados que davam conta de um total de 1000 arquivos de empresa até então recenseados. Na Bélgica, ambos os autores referenciam as iniciativas da Association pour la Valorisation des Archives d'Entreprises, fundada mais recentemente, em 1985, com o intuito de promover, preservar e dar acesso aos fundos dessa natureza, bem como a colaboração desta associação com os Archives Genéráles du Royaume e com os Archives de l'Éttat dans les Provinces. No que toca à França, referem inicialmente a criação, em 1949, pela Direção dos Arquivos do país, de um plano bem-sucedido, motivado por interesses históricos, idealizado para salvaguardar a documentação das empresas. 
Ainda, mais recentemente, em 1994, elogiam a criação, de um departamento afeto aos Arquivos Nacionais - o chamado Serviço de Arquivos Econômicos - dedicado a recuperar e a organizar estes tipos de fundos, embora, ponderem que um dos projetos mais importantes levados a cabo no país tenha sido apresentado 10 anos antes, em 1983, com vista a criar cinco centros regionais de "arquivos do mundo do trabalho", uma vez mais com a finalidade de preservar os fundos documentais das empresas que voluntariamente quisessem depositar os seus fundos nestes arquivos. A este respeito, Nuñez Fernández (2000) destaca que o primeiro centro a funcionar em tais moldes terá sido o de Roubaix.

Além destas importantes iniciativas, identificamos também o caso dinamarquês. Neste país, e no ano de 1948, segundo Amatori e Jones (2003) surgiria o National Danish Business Archives, instituição que como o próprio nome indica, dedicaria a sua atenção à aquisição voluntária de acervos empresariais, de modo a documentar e a preservar essa importante faceta da história do país, adquirindo assim uma documentação histórica representativa de cinco séculos (do XVI ao XX), e dando a conhecer os seus conteúdos ao público. Esta instituição, independente nas suas origens e sendo esse um aspecto a louvar, após algumas mudanças de localização passaria a integrar, a partir do ano de 1992, os arquivos estatais holandeses.

Ainda, apoiados pelas reflexões de González Pedraza (2010b, p. 4142), citamos como exemplo o caso italiano, em que se sobressai a empresa Fiat, que em parceria com a administração pública inicia, em 1971, um estudo na área dos arquivos empresariais. Mais adiante, em 1987, essa mesma empresa começa a identificar os seus fundos, processo que culmina na criação de um arquivo aberto aos investigadores. $O$ mesmo autor menciona a publicação de inventários, na década de 1990, por empresas italianas do setor bancário. Outras iniciativas de relevo, neste país, e referenciadas pelo autor, foram: a criação, em 1983, e o papel ativo desempenhado posteriormente pela Associazione di Studi e Storia dell'Impresa, bem como a criação de um grupo de trabalho devotado aos arquivos empresariais, no âmbito da Associação Nacional dos Arquivistas.

Já fora da Europa, Nuñez Fernández (2000, p. 105-109) destaca os Estados Unidos, país que como sabemos vem imprimindo, e de forma pioneira, desde o início dos anos 40, uma forte política de gestão documental nos arquivos públicos. Ali, conforme diz o autor, identificamse as primeiras iniciativas no meio empresarial, já na década de 1920, impulsionadas por sociedades científicas e por universidades privadas, de que são exemplos a Business Historical Society, de Boston, que juntamente com a Universidade de Harvard e com o Massachusetts Institute of Technology - MIT, colocam em prática, no ano de 1925, um centro destinado a recolher e a organizar os fundos da sociedade de 
Os arquivos empresariais em Portugal: do tradicional ao cloud computing
António Muñoz Cañavate; Maria Gracinda Barata Monteiro; Maria Cristina Vieira de Freitas; Maria Manuel Borges

Boston, e que mais tarde dará lugar à Baker Library, de Harvard², instituição devotada à investigação da história econômica e empresarial do país.

Finalmente, no que toca à América do Sul, e mais precisamente ao Brasil, Coraiola (2012, p. 258-262), num interessante estudo sobre a importância dos arquivos empresariais para a história administrativa do país, destaca alguns marcos legislativos e institucionais, a partir de 1960, entre os quais: a promulgação da Lei no 8.159, de 1991 (BRASIL. Presidência da República, 1991), ou Lei de Arquivos, juntamente com o Decreto no 4.073, de 2002 (BRASIL. Presidência da República, 2002) e com a Resolução no 19, de 2003 (BRASIL. Presidência da República, 2003), que a complementam; a criação de uma câmara setorial, no âmbito do Conselho Nacional de Arquivos (CONARQ), designada "Arquivos de Empresas Privatizadas ou em Processo de Privatização"; a realização de um censo das instituições arquivísticas brasileiras, a partir da década de 2000, culminando com a instituição do "Cadastro Nacional de Entidades Custodiadoras de Acervos Arquivísticos", no ano de 2009.

No Quadro 1, e a modo de síntese, resumimos a informação relativa às iniciativas anteriormente apresentadas.

Quadro 1 - Algumas iniciativas internacionais, no âmbito da preservação dos arquivos empresariais

\begin{tabular}{|c|c|c|c|}
\hline País & $\begin{array}{l}\text { Datas } \\
\text { associadas }\end{array}$ & Instituições & Objetivo geral \\
\hline Alemanha & 1906 & $\begin{array}{llc}\text { Arquivo } & \text { histórico } & \text { (Rheinisch- } \\
\text { Wetfalischer } & \text { Wirtschaftarchiv) }\end{array}$ & 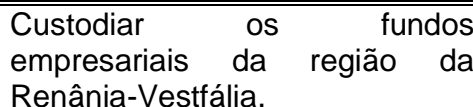 \\
\hline Suíça & 1910 & $\begin{array}{l}\text { Arquivo histórico (Schweizerischen } \\
\text { Wirtschaftarchiv) }\end{array}$ & $\begin{array}{l}\text { Recolher a documentação de } \\
\text { sociedades comerciais. }\end{array}$ \\
\hline Holanda & $1914 ; 1935$ & $\begin{array}{l}\text { Royal Dutch Shelle; Instituto Nacional } \\
\text { de História Social }\end{array}$ & $\begin{array}{l}\text { Recuperar os fundos dedicados } \\
\text { à história social, econômica e } \\
\text { comercial do país. }\end{array}$ \\
\hline $\begin{array}{l}\text { Estados } \\
\text { Unidos }\end{array}$ & 1925 & $\begin{array}{l}\text { Business Historical Society; } \\
\text { Universidade de Harvard; MIT }\end{array}$ & $\begin{array}{l}\text { Recolher e organizar os fundos } \\
\text { dedicados à investigação da } \\
\text { história econômica e empresarial } \\
\text { do país. }\end{array}$ \\
\hline Reino Unido & 1934 & Business Archives Council & $\begin{array}{l}\text { Recolher e preservar os arquivos } \\
\text { empresariais; recensear os } \\
\text { arquivos históricos de empresas } \\
\text { do país. }\end{array}$ \\
\hline Dinamarca & $1948 ; 1992$ & $\begin{array}{l}\text { National Danish Business Archives; } \\
\text { Arquivos Estatais (Erhvewsarkivet) }\end{array}$ & $\begin{array}{l}\text { Adquirir, organizar, preservar e, } \\
\text { mais recentemente, dar acesso } \\
\text { aos arquivos empresariais. }\end{array}$ \\
\hline França & $1949 ; 1994$ & $\begin{array}{l}\text { Direção dos Arquivos da França } \\
\text { (Arquivo Nacional da França); Serviço } \\
\text { de Arquivos Econômicos (Arquivo } \\
\text { Nacional da França) }\end{array}$ & $\begin{array}{l}\text { Salvaguardar, organizar e dar } \\
\text { acesso aos fundos empresariais. }\end{array}$ \\
\hline Itália & $1971 ; 1983$ & $\begin{array}{lc}\text { Empresas privadas (Fiat e setor } \\
\text { bancário); Administração pública; }\end{array}$ & $\begin{array}{l}\text { Salvaguardar, organizar e dar } \\
\text { acesso aos fundos empresariais. }\end{array}$ \\
\hline
\end{tabular}

\footnotetext{
${ }^{2}$ Atualmente vinculada à Harvard Business School. Disponível em: <http://www.library.hbs.edu>. Acesso em: 21 set. 2016.
} 
Os arquivos empresariais em Portugal: do tradicional ao cloud computing
António Muñoz Cañavate; Maria Gracinda Barata Monteiro; Maria Cristina Vieira de Freitas; Maria Manuel Borges
Bélgica $\quad 1985$
Associazione di Studi e Storia dell'Impresa; Associação Nacional dos Arquivistas (grupo de trabalho)

Association pour la Valorisation des Archives d'Entreprise; Archives Genéráles du Royaume; Archives de l'Éttat dans les Provinces

1982, 2002- Lei de Arquivos e legislação 2003; 2009 complementar; câmara setorial dedicada aos arquivos de empresas (CONARQ); Censo e Cadastro Nacional de Instituições Arquivísticas $\begin{array}{lll}\text { Promover, } & \text { preservar e dar } \\ \text { acesso } & \text { aos } & \text { arquivos }\end{array}$ empresariais.

Proporcionar medidas de proteção, de preservação e de acesso aos arquivos, com incidência direta ou indireta nos acervos empresariais.

Fonte: NUÑEZ FERNÃNDEZ (2000); AMATORI; JONES (2003); GONZÁLEZ PEDRAZA (2010b); CORAIOLA (2012).

O Quadro 1 dá-nos uma amostra não probabilística e intencional de ações desencadeadas, no passado, algumas das quais com alcance no presente, no âmbito dos arquivos empresariais, sobretudo no contexto europeu. Evidentemente, chama-nos a atenção o fato de que quer no que diz respeito aos objetivos, voltados para a constituição e a proteção dos arquivos empresariais e também para a questão da organização, e mais recentemente do acesso à informação, quer no que toca à titularidade e ao papel desempenhado pelas instituições que apoiaram estas iniciativas, as coincidências são notáveis, sugerindo alguma tendência para a replicação de modelos, resguardadas as devidas adaptações. Algo variadas, no entanto, são as datas em que as mesmas se realizaram, e que abarcam um período cronológico de quase um século.

No presente, conforme verificamos, alguns dos mais proeminentes Arquivos Nacionais, quer da Europa, quer de outras partes, estão a apostar em estratégias conjuntas e que contemplam os arquivos empresariais. No Reino Unido, por exemplo, mencionamos a existência de programas desencadeados pelo The National Archives ${ }^{3}$ ou pelo Business Archives Council ${ }^{4}$ ou, ainda, pelo Scothish Business Archive, ancorado na Universidade de Glasgow ${ }^{5}$. Nos Estados Unidos, e a título ilustrativo, identificamos o papel desempenhado pela Business Archives Section, vinculada à Sociedade dos Arquivistas Americanos - SAA ${ }^{6}$, que em 1997 lançou o Directory of Corporate Archives in the United States and Canada ${ }^{7}$. Ao avaliar esta experiência, uma década depois, Tousey e Adkins (2007) referiram que, embora não houvesse nos Estados Unidos uma legislação que obrigasse à preservação dos arquivos de empresa, eram mais de trezentas as instituições cadastradas no diretório criado para o efeito, o que per se demonstrava a importância atribuída ao empreendimento. Igualmente, no país vizinho, que também participaria desta iniciativa, referimos a produção recente de uma "cartilha", publicada

\footnotetext{
${ }^{3}$ Disponível em: <http://www.nationalarchives.gov.uk/archives-sector/projects-and-programmes/businessarchives-strategy/>. Acesso em: 29 set. 2016.

${ }^{4}$ Disponível em: <http://www.businessarchivescouncil.org.uk/>. Acesso em: 30 set. 2016.

${ }^{5}$ Disponível em: <http://www.gla.ac.uk/services/archives/collections/business/>. Acesso em: 30 set. 2016.

${ }_{7}^{6}$ Disponível em: <http://www2.archivists.org/groups/business-archives-section>. Acesso em: 30 set. 2016. Disponível em: <http://www2.archivists.org/groups/business-archives-section/directory-of-corporatearchives-in-the-united-states-and-canada-introduction>. Acesso em: 30 set. 2016.
} 
pela Associação dos Arquivistas Canadenses (ACA), voltada para a sensibilização dos líderes de empresas para o valor desta documentação e para os benefícios em apostar na sua organização, preservação e acesso ${ }^{8}$. Um exemplo semelhante encontramos na Grã-Bretanha, com a publicação, pelos Arquivos Nacionais, no ano de 2009, de um guia para a gestão dos arquivos de empresa ${ }^{9}$.

Além destes, realçamos dois outros empreendimentos relativamente atuais. Primeiramente, referimos o papel desempenhado pelo Conselho Internacional de Arquivos (CIA) ${ }^{10}$, por meio da Seção de Arquivos Empresariais (Section on Business Archives - SBA). Tal como se indica na sua página Web, esta Seção, criada em 1990, inclui um leque de objetivos ambiciosos, entre os quais: promover a cooperação e a comunicação entre os arquivos de empresa e os arquivistas, alargando o interesse por estes acervos; desenvolver orientações para a sua avaliação; promover o seu acesso; cooperar com os arquivos públicos responsáveis pela sua manutenção; promover, individualmente ou em conjunto, encontros e oficinas devotadas ao tema. Em segundo lugar, mencionamos a existência do Portal Europeu de Arquivos ${ }^{11}$, plataforma multilíngue em que podemos encontrar informações acerca dos arquivos dos diferentes países comunitários, entre os quais se encontram os de natureza empresarial, bem como dos seus serviços.

No plano das críticas, algumas das iniciativas acima mencionadas nem sempre foram consideradas as mais apropriadas. Na década de 70, por exemplo, Rider (1975-1976, p. 93-94) lançava uma nota, censurando o fato de muitas das estratégias europeias voltadas para os arquivos de empresa apostarem unicamente no poder público e nos arquivos estatais como forma de garantir a preservação desses acervos. Segundo então dizia, nesse caso enquadravam-se muitas das iniciativas que se vinham destacando no continente, entre as quais a Inglaterra e a Alemanha. A exceção deveria ser aplicada à Dinamarca, que a seu ver configurava um caso de sucesso, justamente pelo fato de os seus arquivos de empresa terem sido entregues inicialmente a um consórcio independente, surgido do interesse das próprias empresas, só mais tarde apoiado pelos arquivos estatais (como também mencionamos mais atrás). No Canadá, na mesma época, segundo comentava o autor, a situação dos arquivos de empresa não era animadora, havendo documentação em risco de desaparecimento, pela aposta numa política inversa, ou seja, na ação individual e não nas estratégias conjuntas, que envolvessem as empresas e, principalmente, os seus líderes, normalmente negligentes quanto à importância do

8 Disponível em: <http://www.archivists.ca/sites/default/files/Attachments/Outreach_attachments/BusinessArchives-Booklet.pdf>. Acesso em 9 nov. 2016.

9 Disponível em: <http://www.nationalarchives.gov.uk/documents/information-management/corporatememory.pdf>. Acesso em: 9 nov. 2016.

10 Disponível em: <http://www.ica.org/en/ica-professional-sections/section-business-archives-sba>. Acesso em: 30 set. 2016.

Disponível em:

<https://www.archivesportaleurope.net/home;jsessionid= 9D4577FF43A855D621520E7760E320CF>. Acesso em: 30 set. 2016. 
património documental existente nos seus depósitos. O autor criticava também o fato de o Conselho Internacional de Arquivos não ter criado, à data, um comitê de proteção destes arquivos, muito embora esta decisão tivesse sido concertada um ano antes, em Londres, numa conferência dedicada à discussão desses assuntos. Como vimos, esse comitê a que se referia Rider (1975-1976), viria a tornar-se realidade quase duas décadas depois, em 1990. Já no que respeita às demais iniciativas, podemos dizer que algumas delas se firmariam, nesta mesma década, alterando significativamente o panorama algo negativo "pintado" pelo autor. No entanto, a nosso parecer, continua sendo extremamente pertinente a observação de que as estratégias de salvaguarda e de divulgação dos arquivos empresariais não devem depender exclusivamente da iniciativa e da responsabilidade das instituições públicas de arquivo, apostando-se, ao contrário, em ações que se repartam pelas empresas e pelos seus líderes, de modo a ampliar o impacto dos resultados.

\section{Os arquivos empresariais: o caso português}

\subsection{Iniciativas jurídicas}

Num estudo realizado há mais de uma década, Paulo (2005) cita o que considera ter sido um intenso trabalho normativo desenvolvido em Portugal, em pouco mais de um século, abrangendo períodos em que se destacaram, primeiramente, no texto dos dispositivos promulgados, objetivos tais como a proteção e a valorização e, mais recentemente, a avaliação e a seleção dos documentos, entre os quais os de caráter empresarial. $O$ autor referencia inicialmente aquele que terá sido o precursor dos demais na matéria: trata-se do Código Comercial, datado de 1888, do qual se destaca o artigo 40, situado no "Título IV Da Escripturação", em que não apenas se obrigava a conservar certos tipos de documentos resultantes das atividades das empresas, como também se fixavam prazos para o efeito. Vejamos como: "[t]odo o commerciante é obrigado a archivar a correspondencia e telegrammas que receber, os documentos que provarem pagamentos e os livros da sua escripturação comercial, devendo conservar tudo pelo espaço de vinte anos" (PORTUGAL. Código Comercial, 1888, p. 1966). O referido artigo é complementado pelo seguinte, o 41 , onde se lê que: "[n]enhuma autoridade, juízo ou tribunal póde fazer ou ordenar varejo ou diligencia alguma para examinar se o comerciante arruma ou não devidamente os seus livros de escripturação mercantil" (PORTUGAL. Código Comercial, 1888 , p. 1966). Contudo, e a este respeito, mais adiante, na mesma secção do dispositivo, adverte-se o seguinte: se um comerciante, por qualquer razão, não "arrumar" devidamente os assentos nos seus livros, tal ato, em juízo, constituirá prova contrária. 
Se por um lado esta norma obrigava os comerciantes a manterem um arquivo dos seus documentos, por outro, conforme analisa Oliveira (1966, p. 94), na sua concepção não se contemplou convenientemente a questão das medidas concretas a adotar para promover a organização da informação nesses arquivos, tanto menos para a sua avaliação ou os meios adequados à sua preservação, reduzindo-se assim a sua eficácia, uma vez que a ideia explícita no documento era a de "conservar tudo", sem estabelecer "como", e por um prazo fixo - 20 anos - , após o qual a documentação, por não mais constituir prova, poderia ser eliminada. Como consequência,

[a]s organizações abrangidas por aquela disposição legal, passaram a considerar a obrigação de guardar documentos como um mal necessário, passando o arquivo à categoria de uma espécie de armazém onde se deveria amontoar, mais ou menos ordenadamente, a mais variada gama de documentos, desde as cartas e livros de escrituração mercantil, até aos apontamentos, rascunhos e outros elementos de trabalho. Dentro do mesmo espírito, também ao pessoal que trabalha nos arquivos não tem sido atribuída a categoria que lhe deve competir até porque, normalmente, esse pessoal não tem qualquer especialização, e antes pelo contrário, se destaca para esse trabalho geralmente o pessoal menos qualificado e capaz que se emprega na organização (OLIVEIRA, 1966, p. 94).

Passados quase cem anos, com a promulgação do Decreto-Lei $n^{\circ}$ 41, de 1972 (PORTUGAL. Ministério da Justiça, 1972) o prazo de conservação previsto na legislação anterior sofreria uma redução, de 20 para 10 anos. Em seguida, seriam aprovados dois outros dispositivos com algum impacto nos arquivos de empresa. Nesse caso, referimo-nos à publicação da Portaria no 703, de 1976 (PORTUGAL. Ministério das Finanças, 1976) e do Decreto-lei no 29, de 1972 (PORTUGAL. Presidência do Conselho. Secretaria Geral, 1972), pelo qual se estendeu, à generalidade dos serviços públicos, 0 uso da microfilmagem dos documentos de arquivo, com a consequente inutilização dos originais, estabelecendo-se normas para a sua uniformização e procedimentos. Conforme Paulo (2005), este último dispositivo tinha como alvo as instituições bancárias e as seguradoras, bem como os documentos de caráter fiscal e os produzidos ou acumulados nos serviços dependentes do Estado, daí a sua relevância para os arquivos de empresa.

De igual modo, legislados também seriam outros aspectos relacionados com a salvaguarda, em território nacional, dos arquivos e dos bens culturais pertencentes às empresas privadas, nacionais ou estrangeiras, de modo a evitar a sua transferência para o exterior, incorrendo-se em perda de patrimônio, imputando-se a responsabilidade pela sua manutenção aos respectivos responsáveis. É o caso, por 
exemplo, do Decreto-Lei no 429, de 1977 (PORTUGAL. Secretaria de Estado da Cultura, 1977), que, apesar de ter sido considerado conservador e pouco eficaz (CORDEIRO, 2001a; CRUZ; DAMAS, 2008), no primeiro ponto do Artigo 1 , estabeleceu que esses arquivos, pela sua relevância científica, política ou econômica, deveriam ter a sua saída do país proibida. Aliás, este objetivo tem sido apontado como a razão subjacente para a existência do referido dispositivo. Vejamos o excerto:

São tidos por inalienáveis e insuscetíveis de saírem de território nacional os arquivos ou bens culturais, históricos e científicos das empresas privadas, nacionais ou estrangeiras, que, pela sua antiguidade, relevância económica ou influência política hajam tido grande projeção na vida nacional em qualquer tempo (PORTUGAL. Secretaria de Estado da Cultura, 1977, p. 2498, grifo nosso).

Mais adiante, em meados dos anos 80 , viria à luz a Lei no 13 , de 1985 (PORTUGAL. Assembleia da República, 1985), ou lei do património, que dispunha sobre as formas e o regime de proteção do património cultural português, bem como sobre as garantias e as sanções aplicáveis. Esta legislação é ampliada, mais recentemente, pela Lei no 107, de 2001 (PORTUGAL. Assembleia da República, 2001), em que, para além de se estabelecerem as bases da política e do regime de proteção e de valorização do património cultural do país, de um modo geral, são discorridos, nos artigos 80 a 83 do "Capítulo III Do Património Arquivístico", aspectos específicos dos arquivos, tais como as definições, a categorização, os critérios e as formas de proteção e de valorização (PORTUGAL. Assembleia da República, 2001, p. 5822-5823). De especial interesse, entre outros, é o ponto 1 do artigo 80 deste dispositivo, em que se confirma textualmente que: "[i]ntegram o património arquivístico todos os arquivos produzidos por entidades de nacionalidade portuguesa que se revistam de interesse cultural relevante" (PORTUGAL. Assembleia da República, 2001, p. 5822); ou, ainda, a alínea b) do artigo 83, em que se determina a classificação "como de interesse nacional" dos arquivos públicos com mais de 100 anos (PORTUGAL. Assembleia da República, 2001, p. 5823).

Ainda, no final dos anos 80, um outro dispositivo considerado relevante para a comunidade arquivística portuguesa viria a substituir alguma da regulamentação em vigor ou mesmo regulamentar aspectos não de todo tocados pelos instrumentos predecessores. Assim, nos termos do exposto no artigo 1 do Decreto-Lei no 447, de 1988 (PORTUGAL. Presidência do Conselho de Ministros, 1988, p. 4885), revogando o Decreto-Lei no 29, de 1972 (PORTUGAL. Presidência do Conselho. Secretaria-Geral, 1972), antes mencionado, passaria a regular o préarquivamento da documentação, estabelecendo um enquadramento para a definição de políticas arquivísticas na área da avaliação, da seleção e da eliminação de documentos, entre outras medidas, tendo como foco os 
serviços da administração direta e indireta do Estado, as autarquias locais, as Instituições Particulares de Solidariedade Social (IPSS), as pessoas coletivas de utilidade pública administrativa e outras entidades públicas ou privadas cujos arquivos fossem declarados de relevante interesse cultural. Com este abrangente dispositivo, dar-se-ia um passo à frente na criação de uma política de gestão documental para os arquivos públicos portugueses.

Algum tempo depois, num outro documento devidamente sublinhado por Paulo (2005), o Decreto-Lei no 121, de 1992 (PORTUGAL. Presidência do Conselho de Ministros, 1992, p. 3146), que se insere "no âmbito de uma revisão global do regime jurídico dos arquivos, iniciada pelo Decreto-Lei no 447, de 1988", atribuir-se-ia importância à regulamentação dos arquivos empresariais, estabelecendo-se os princípios aplicáveis à gestão dos documentos relativos aos recursos humanos, financeiros e patrimoniais dos serviços da administração direta e indireta do Estado. Quanto à substituição dos suportes, no artigo 5 (PORTUGAL. Presidência do Conselho de Ministros, 1992, p. 3147), o referido decreto tornaria a sua autorização como algo da responsabilidade do órgão coordenador da política arquivística nacional. Nas nossas pesquisas, verificamos que para a regulamentação deste Decreto-Lei foi criado, pelo Despacho Conjunto no 427, de 1999 dos Ministérios das Finanças e da Cultura (PORTUGAL. Ministério das Finanças. Ministério da Cultura, 1999), um grupo de trabalho constituído por representantes do Instituto dos Arquivos Nacionais/Torre do Tombo e da Secretaria-Geral, Direção-Geral do Orçamento e Direção-Geral do Património, do Ministério das Finanças. Fato é que, para além de um declarado interesse pela identificação sistemática deste tipo de documentação, uma outra finalidade do mencionado diploma terá sido a de criar condições adequadas para iniciar um processo de normalização das designações das séries arquivísticas existentes nesses acervos, bem como do seu destino final. A corroborar estas asserções, destacamos um excerto da introdução de dito dispositivo, que dispõe sobre o seguinte:

[p]rocura-se racionalizar o ciclo de vida dos documentos de arquivo, controlando o seu crescimento através da avaliação e seleção, minimizando-se os custos da conservação de todos os documentos produzidos como resultado das múltiplas atividades do Estado. Se a conservação dos documentos de menos valor ameaça a sobrevivência dos mais valiosos, torna-se legítimo adotar medidas arquivísticas que garantam a conservação permanente destes.

Nessa medida, uma política arquivística coerente tende não só a tornar mais racional e rentável a utilização e a conservação administrativa dos documentos e da informação como promove a adequada preservação dos acervos de conservação permanente, facilitando a tarefa da investigação histórica (PORTUGAL. Presidência do Conselho de Ministros, 1992, p. 3146). 
Os excertos anteriores demonstram a evolução dos principais aspectos legislados por alguns dos mais importantes dispositivos relacionados com o tema, num intervalo de pouco mais de cem anos. Assim, nota-se, por exemplo, que se num momento a avaliação não é contemplada, no outro, todavia, é justificada com medidas "arquivísticas" racionais de seleção e de conservação dos documentos considerados "valiosos" para a investigação histórica e, portanto, de conservação permanente. Conquanto se reconheça algum conservadorismo nesses dispositivos, não se pode negar que representam um avanço na política arquivística nacional. Trata-se, pois, de uma amostra intencionalmente selecionada de um conjunto conhecido de pouco mais de uma centena de diplomas que direta ou indiretamente tiveram impacto nos arquivos portugueses, e que adotaram uma perspectiva primeiramente patrimonialista e posteriormente pragmática, num intervalo que vai do fim do século XIX até ao final do século XX.

Mais recentemente, e no que toca aos interesses particulares dos arquivos de empresa, pelo Decreto-Lei no 76-A, de 2006 (PORTUGAL. Ministério das Finanças. Ministério da Administração Pública. Ministério da Justiça, 2006), procedeu-se a uma revisão dos textos até então vigentes sobre o assunto. O referido dispositivo, presente no Programa do XVII Governo Constitucional de Portugal, entre outras medidas, atualiza e flexibiliza os modelos de gestão das sociedades anônimas, adotando medidas destinadas à simplificação e à eliminação de atos e de procedimentos notariais e registrais, além de aprovar um regime jurídico voltado para a dissolução e a liquidação de entidades comerciais. Neste enquadramento, e citando o conteúdo do referido Programa, dispõe que "os cidadãos e as empresas não podem ser onerados com imposições burocráticas que nada acrescentem à qualidade do serviço" (PORTUGAL. Ministério das Finanças. Ministério da Administração Pública. Ministério da Justiça, 2006, p. 2328-2) e, ainda, que "no interesse conjunto dos cidadãos e das empresas, serão simplificados os controlos de natureza administrativa, eliminando-se actos e práticas registrais e notariais que não importem um valor acrescentado e dificultem a vida do cidadão e da empresa (como sucede com a sistemática duplicação de controlos notariais e registrais)". Quanto ao prazo de conservação previsto anteriormente, o mesmo mantém-se inalterado. No entanto, abrem-se novas possibilidades, no que diz respeito aos suportes a serem utilizados na preservação dos documentos comerciais. Estas constatações podem ser verificadas nos seguintes excertos do art. 40, Seção III da referida legislação (PORTUGAL. Ministério das Finanças. Ministério da Administração Pública. Ministério da Justiça, 2006, p. 2328-50):

1. Todo o comerciante é obrigado a arquivar a correspondência emitida e recebida, a sua escrituração mercantil e os documentos a ela relativos, devendo conservar tudo pelo período de $\mathbf{1 0}$ anos. 
2. Os documentos referidos no número anterior podem ser arquivados com recurso a meios electrónicos" (PORTUGAL. Ministério das Finanças. Ministério da Administração Pública. Ministério da Justiça, 2006, p. 2328-50, grifos nossos).

No entanto, essas referências diretas aos "meios eletrônicos" como "novos" suportes a serem utilizados na conservação dos documentos de arquivo são consideradas pouco expressivas ou mesmo insuficientes, restringindo-se o seu impacto, uma vez que não avançam com a clara designação das medidas requeridas quer para a sua proteção, quer para a sua utilização ou para a sua continuidade ao longo do tempo.

Em suma, a análise dos dispositivos anteriores evidencia, num primeiro momento, o valor histórico e patrimonial atribuído à documentação empresarial, bem como a sua relação com a história, sendo estas situações constatadas também por outros estudiosos que se debruçaram sobre o assunto (COSTA, 1979; SILVA, 1989; RODRIGUES, 1993; RODRIGUES, 1995; DAMAS, 2009; CORAIOLA, 2012). Também nos parece evidente o fato já constatado por alguns dos autores previamente mencionados, de que os arquivos empresariais em Portugal são matéria ainda mal legislada ou insuficientemente atendida pelos poderes públicos vigentes, em distintos períodos da história arquivística do país. Mais ainda que, não obstante a sua sobejamente conhecida importância dentro e fora de Portugal, a legislação que os ampara, que de resto é esparsa, peca, em vários momentos, pela incapacidade de determinar medidas concretas e capazes de promover a sua proteção e a sua valorização, não apenas de direito, mas também de fato.

\subsection{Iniciativas institucionais}

No âmbito da Administração Pública portuguesa, de acordo com Paulo (2005, p. 11), as políticas voltadas para os arquivos de empresa vêm sendo orientadas em dois sentidos: um, interno, relacionado à inclusão dos arquivos na estrutura das organizações, de modo a garantir a preservação dos documentos em função de um valor probatório que thes posa vir a ser reclamado, no futuro; e outro, externo, vinculado à necessidade, cada vez mais presente, de obter acesso aos fundos documentais, por parte dos cidadãos, e da exigência de uma maior transparência nas ações, por parte das organizações detentoras dos documentos. Portanto, e a modo de síntese, das afirmações do autor podemos concluir que a um tradicional dever de responsabilidade e de custódia, veio somar-se um outro, não menos exigente, porque fruto dos novos tempos: o de partilha da informação.

Os arquivos empresariais portugueses sofreram influências das ações produzidas em outros países europeus, apoiando-se, pela relativa proximidade, nos exemplos vindos do contexto francês ou mesmo 
espanhol. Assim, tal como em outros países (SENÉCAL, 2013), vários destes movimentos em defesa dos arquivos empresariais surgiram na esfera acadêmica, já que muitos dos seus empresários não se encontravam sensibilizados para a preservação dos próprios fundos documentais (GUIMARÃES, 2001). Não obstante, de modo a traçarmos uma cartografia minimamente compreensiva das principais iniciativas nesse âmbito, convém realçar o papel desempenhado por algumas destas instituições, situadas especialmente no setor público, bem como as suas ações mais visíveis.

Com efeito, a preocupação por estes depósitos nasceu em Portugal, desde há décadas, alimentada por uma vertente histórica, e por uma necessidade crescente de proteção dos arquivos produzidos e acumulados pelas empresas, como uma ferramenta para a história, o que permitiu refletir acerca da sua importância, do ponto de vista documental e informacional, para o conhecimento, no futuro, da memória coletiva dessas organizações. Já no fim dos anos 70, Costa (1979) havia chamado a atenção para o fato de que questão da salvaguarda dos arquivos históricos empresariais, dada a relevância do tema, deveria ser prioritária. Outras propostas, como refere Silva (1989), chegariam mesmo ao limite de indicar os arquivos distritais como responsáveis pela salvaguarda dessa documentação, tendência ainda hoje presente no país, implicando uma alteração na legislação, de modo a conciliar os interesses públicos com os direitos legítimos dos proprietários.

Mesmo em face destas importantes iniciativas, Damas (2009, p. 10) refere que os exemplos de preservação dos fundos históricos das empresas portuguesas são relativamente escassos. Todavia, aponta aqueles que considera importantes, entre os quais: 0 trabalho desenvolvido por instituições tais como o Arquivo Histórico/Centro de Documentação do Museu dos Lanifícios, subordinado à Universidade da Beira Interior, responsável pela reunião de algumas dezenas de fundos documentais de empresas já extintas; bem como o papel desempenhado pelo Grupo de Estudos da História da Viticultura Duriense, de assinalável relevância para a preservação de arquivos provenientes de empresas do setor agrícola. Junto destas iniciativas, segundo diz, também podemos encontrar casos pontuais de Câmaras Municipais, que se responsabilizam pela salvaguarda dos arquivos de empresas já desaparecidas e situadas no seu raio de ação.

Pese embora todo este empenho, as iniciativas portuguesas se encaixam, por norma, nos ideais de defesa do patrimônio documental. A este respeito, e reportando-se à ideia de valorização dos documentos empresariais como fontes para a arqueologia industrial, conforme ponderou Damas (1999-2000, p. 222),

[a]través da documentação produzida e recebida pelas empresas no decorrer das suas actividades quotidianas, a informação contida nos documentos de arquivo desvenda a vida do colectivo, faculta 
conhecimentos que nos permitem determinar os momentos da sua expansão ou estagnação, dá-nos elementos que habilitam conhecer a acção das personalidades que as geriram, determinando de um modo ou de outro o seu destino, enfim, pela informação veiculada nos documentos podemos sentir o pulsar da empresa.

\section{3):}

Da mesma maneira e para o próprio Damas (1999-2000, p. 222-

[o]s documentos de arquivo cujo interesse histórico obriguem à sua conservação definitiva são decisivos em estudos de história económica, e isto só para abordarmos um dos muitos ângulos de análise que se nos oferecem... Assim entendidos, os conjuntos documentais "participam" na elaboração da história da empresa, da região, do país, ao serem comunicados através dos instrumentos de descrição próprios (guias, inventários e catálogos), a investigadores multifacetados, com interesse e sensibilidade para a política empresarial, que neles colhem preciosa informação para o tema que investigam, seja para a história da empresa, seja no âmbito mais vasto da história económica e social.

Nesta mesma linha e em favor de uma identificação dos seus potenciais utilizadores, Mendes (2001-2002, p. 382) diz-nos que esses arquivos são frequentados por aqueles que se dedicam ao esclarecimento de temas tradicionais nas empresas (como, por exemplo, exportações e importações ou os impostos aduaneiros), mas também por aqueles investigadores que tratam de assuntos tão diversos como as invenções e as inovações tecnológicas, a arquitetura industrial e a evolução dos processos produtivos ligados ao conceito de cultura científica, sendo, nessa acepção, ferramentas fundamentais para a história da economia e das empresas. O autor também assinala que para estabelecer uma política de proteção desses documentos, em Portugal, deve-se começar pelos arquivos das empresas públicas, que podem servir de modelo às privadas, sobretudo às mais antigas, já que no país é relativamente grande o número de empresas criadas entre o fim do século XVII e o início do século $X X$. Igualmente, diz que dar valor a estes arquivos pode servir para dinamizar a história local, por meio das empresas radicadas no seu espaço geográfico, o que pode servir, também, para potenciar a memória e a identidade das suas populações e fomentar o turismo cultural.

De igual modo, há cerca de uma década e meia, Cordeiro (2001a; 2001b) já havia ponderado que uma política portuguesa para os arquivos empresariais não poderia dever-se somente a uma necessidade de os gerir adequadamente, mas também ao imperativo de evitar que o desaparecimento de empresas, como consequência do turbulento e conturbado panorama econômico nacional, desse lugar à perda de importantes acervos documentais, no geral, e em particular aos referentes 
às empresas industriais, cujos fundos eram representativos de eventos tão significativos para a história do país como a introdução de tecnologias, ou a conquista de mercados, estando tudo isso relacionado com o conceito mais lato de patrimônio documental empresarial. $O$ autor também propunha a adoção de diferentes medidas para sensibilizar as empresas na defesa e na recuperação dos seus arquivos históricos, entre elas a realização de campanhas junto destas e das Associações Industriais e Comerciais. Recentemente, encontramos em Damas (2009, p. 5-6) algum eco destas ideias, propondo-se a sua aplicação a um setor bastante conhecido e rentável para o país - o do vinho do Porto - , sugerindo-se uma abertura dos arquivos das adegas para o estudo, argumentando que este poderia ser um artifício a usar, por exemplo, como campanha de publicidade positiva permanente, relativamente aos concorrentes de outros países.

Paralelamente à atuação destas instituições, importa destacar o papel desempenhado pela agência nacional de arquivos, em Portugal, que teve o seu reconhecimento como Arquivo Nacional no ano de 1911, passando à dependência do Ministério da Cultura no ano de 1985. Esta instituição sofreu uma fusão, no ano de 1992, com Instituto Português de Arquivos (IPA), criado alguns anos antes pelo Decreto-Lei no 152, de 1988 (PORTUGAL. Presidência do Conselho de Ministros, 1988), da qual resultou a denominação social de Arquivos Nacionais/Torre do Tombo (AN/TT). Anos mais tarde, nesta instituição e por meio da publicação do Decreto-Lei no 60, de 1997 (PORTUGAL. Ministério da Cultura, 1997), foi criada uma divisão que, pelo foco, apresentava ligações com os arquivos empresariais: a Divisão dos Arquivos Intermédios. Atualmente, após algumas alterações na sua designação e nas suas competências, pelo Decreto-Lei no 103, de 2012 (PORTUGAL. Presidência do Conselho de Ministros, 2012) e pela Portaria no 192, de 2012 (PORTUGAL. Presidência do Conselho de Ministros. Ministério das Finanças, 2012), o Arquivo Nacional da Torre do Tombo passa a ser um serviço dependente da Direção-Geral do Livro, dos Arquivos e das Bibliotecas, tendo as suas competências sido fixadas, nesse mesmo ano, ao abrigo do Despacho no 9339, de 2012 (PORTUGAL. Direç̧ão-Geral do Livro, dos Arquivos e das Bibliotecas. Presidência do Conselho de Ministros, 2016).

De igual modo, referimos a criação, pelo Decreto-Lei no 372, de 1998, do Conselho Superior de Arquivos (CSA) (PORTUGAL. Ministério da Cultura, 1998), entidade destinada a concentrar esforços e aprovar recomendações sobre: privatizações e patrimônio arquivístico; gestão de documentos; concepção e planejamento da Rede Nacional de Arquivos (RNA); formação profissional de técnicos de arquivo, arquivos audiovisuais, fonográficos e fotográficos; diagnóstico à situação dos arquivos da Administração Central. Para compor essa nova forma de organização da política arquivística nacional e a funcionar em rede junto com os arquivos centrais, e ao abrigo de legislação própria, nesse caso o 
Decreto-lei no 149, de 1983 (PORTUGAL. Ministério da Cultura e Coordenação Científica, 1983), alterado pelo Decreto-lei no 206, de 1985 (PORTUGAL. Ministério da Cultura, 1985) e pelo Decreto-lei no 248, de 2003 (PORTUGAL. Ministério da Cultura, 2003) também passaram a estar os arquivos Distritais (SOUSA, 2005) e os arquivos municipais (PEIXOTO, $2005)^{12}$, tendo os primeiros sido criados, individualmente ou em conjunto, por meio de uma série cronológica de dispositivos jurídicos publicados ao longo do século XX, mais especialmente entre 1911 e 1965.

No seu conjunto, estas instituições acabam por, na esfera da Administração do Estado, preencher lacunas, tornando-se direta ou indiretamente responsáveis pelas políticas que, no país, vão ao encontro dos diversos interesses expressos pelos arquivos, entre os quais os de empresas, ativas ou extintas.

\subsection{Iniciativas científicas e/ou associativas}

Na passada década, Cruz e Damas (2008) realizaram uma análise SWOT da situação dos arquivos de empresas em Portugal. Entre os pontos fracos assinalaram: i) a sua função secundária, o que na sua opinião replicava a prática arquivística existente ao nível nacional; ii) a escassa sensibilidade das empresas para a gestão dos seus documentos; e iii) a inexistência, em Portugal, de uma tradição focada na preservação dos arquivos empresariais e do seu reconhecimento como fontes para a memória e a história econômica. Entre as ameaças, identificaram: i) a vulnerabilidade e o risco, situações que afetavam uma grande percentagem dos arquivos de empresas no país; ii) o encerramento de empresas, com a consequente desaparição ou eliminação dos seus documentos; iii) a necessidade de atualização da legislação afeta a esses arquivos. Finalmente, entre as oportunidades ressaltaram a produção de um guia de arquivos de empresas em Portugal e entre os pontos fortes mencionaram os vários eventos sobre os arquivos de empresas até então realizados no país. Também deram como exemplos os arquivos históricos das instituições financeiras portuguesas, alegando que incluíam, nos seus acervos, conjuntos completos de documentos, remontando quer às origens destas entidades, quer às sucessivas companhias que a elas se iam integrando.

Num estudo posterior, que abordou a questão da gestão da informação nos arquivos de instituições financeiras portuguesas, Balinha (2012) identificou alguns exemplos de projetos existentes em importantes empresas do país, destacando as pertencentes ao setor bancário ou ao abastecimento de águas, energia e transporte, citando como exemplos: o Banco Espírito Santo, o Banco de Portugal, a Caixa Geral de Depósitos, os Comboios de Portugal e a Empresa Pública de Águas Livres e Eletricidade

12 Uma lista completa dessas instituições encontra-se disponível em: <http://arquivos.dglab.gov.pt/redeportuguesa-de-arquivos/rede-dgarq/arquivos-regionais/>. Acesso em: 10 out. 2016. 
de Portugal. Nesse mesmo estudo, o autor evidenciou os resultados obtidos com a aplicação de um questionário dirigido a cinco dos maiores bancos existentes no país13, entre os quais destacamos: i) o fato de estas instituições, centenárias em alguns casos, conciliarem a existência de arquivos correntes e intermediários com os arquivos históricos, sem haver uma integração de todo o ciclo gestionário da documentação, ao nível organizacional; ii) o fato de a coordenação dos sistemas de gestão eletrônica dos documentos, nestas empresas, não atingir os responsáveis dos arquivos; iii) o fato de os profissionais dedicados a estas tarefas serem, cada vez mais, em número reduzido, e de a documentação em suporte digital ocupar o centro das suas preocupações.

De algum modo, estes estudos corroboram a ideia de que, no que diz respeito aos arquivos empresariais portugueses, o setor bancário destaca-se como um dos mais preocupados com a gestão da sua própria informação, presente ou pretérita, para além de haver, no país, muito o que fazer quer no campo das políticas, quer no plano da legislação e da sensibilização, de modo a colocar esses arquivos como foco das atenções de instituições vinculadas aos setores públicos e privados.

No que diz respeito aos eventos que versam sobre essas matérias, e que foram apontados por esses mesmos autores como exemplos positivos (CRUZ; DAMAS, 2008; BALINHA, 2012), verifica-se que a preocupação e o debate em torno dos arquivos empresariais em Portugal concentram-se, sobretudo, no final dos anos 90 e no início da década de 2000.

Algumas das primeiras iniciativas de relevo, nessa matéria, podem ser imputadas à Associação Portuguesa de Bibliotecários Arquivistas e Documentalistas (APBAD), que se mostrou bastante ativa no tocante à conscientização sobre a importância da gestão desses arquivos. De acordo com Infante (2005, p. 32-33), esta associação, desde a sua criação, em 1973, passaria a reunir os profissionais de informação e a representar Portugal nas federações internacionais especializadas, além de desenvolver programas de formação de técnicos especializados, constituindo uma estrutura de grupos de trabalho que se dedicariam às diversas áreas de atividade dos arquivos e das bibliotecas.

Essas informações são corroboradas por Andrade (2005), quando pondera que no tocante aos arquivos de empresa, desde 1999, a APBAD vem desenvolvendo um projeto de sensibilização junto de empresários e de gestores financeiros, no sentido de os alertar para a importância dos seus arquivos. Nesse intento, constituiu o Grupo de Trabalho de Arquivos Empresariais (GTAE), responsável pela realização de encontros destinados ao debate destes temas (Quadro 2). Entre os principais objetivos deste Grupo, a autora menciona os seguintes: sensibilizar as empresas acerca da necessidade de preservar e de gerir os seus fundos documentais; fomentar e estimular a utilização de normas internacionais; apoiar as

${ }^{13}$ Banco Espírito Santo S. A., Banco Santander Totta S. A., BPI Banco Português de Investimento S. A., Caixa Geral de Depósitos S. A., e Millenium Banco Comercial Português, S. A. 
empresas na organização dos seus arquivos; promover encontros ou atividades de formação direcionados a esses temas (ANDRADE, 2005, p. 100).

Assim, dando cumprimento a este último objetivo, verificamos que o GTAE, de fato, organizou encontros nacionais ou internacionais importantes, cujos propósitos foram, em geral: conhecer as experiências e identificar os problemas com que se defrontavam empresários, gestores e técnicos na área da gestão documental e sensibilizar os responsáveis para a importância da informação de natureza administrativa e do seu tratamento arquivístico. Quanto a algumas das principais conclusões alcançadas ${ }^{14}$, podemos citar: a necessidade de o Estado Português tomar medidas adequadas para preservar a documentação das empresas em processo de falência e/ou extinção; os benefícios a obter com o trabalho conjunto a realizar pelo GTAE e pela Direção do Instituto do Arquivo Nacional/Torre do Tombo na análise e resolução dos problemas; a necessidade de reforçar a colaboração com as associações de empresários e com as instituições ligadas à investigação, para garantir a salvaguarda dos arquivos empresariais; a necessidade de produção de legislação específica, voltada para a salvaguarda e a valorização dos arquivos empresariais; a necessidade de sensibilização dos responsáveis e dos gestores das empresas, quanto à gestão arquivística e à relevância destes arquivos para a história institucional; a necessidade do trabalho conjunto de arquivistas, especialistas em sistemas de informação e tomadores de decisão, na definição de normas, requisitos e procedimentos para garantir a autenticidade, a integridade e $o$ acesso a esses arquivos.

De modo semelhante, Balinha (2012) revela que a Associação Portuguesa de História Económica e Social, por meio do seu Núcleo de Estudos de História Empresarial ${ }^{15}$ (NEHE) promoveu eventos associados ao tema dos arquivos empresariais. Esse autor também indica que a International Faculty for Executives - IFE organizou, em Portugal, uma série de eventos genericamente designados INFODOC ${ }^{16}$, em que se reuniram, ao mesmo tempo, profissionais do setor público e do privado, entre os quais os arquivistas, os profissionais da área da informática e os gestores de empresas. Estes eventos tiveram como objetivo, entre outros temas, a troca de ideias e de experiências no âmbito: da gestão de conteúdos, do workflow, dos arquivos digitais, da organização, da recuperação, da segurança e do armazenamento da informação (Quadro

\footnotetext{
14 As conclusões dos diferentes encontros estão disponíveis em: <http://www.apbad.pt/Seccoes/S_ArqEmpresariais/SAE_act.htm>. Acesso em: 27 set. 2016.

${ }^{15} \mathrm{O}$ Núcleo de Estudos sobre História Empresarial nasceu de uma parceria entre a Faculdade de Economia da Universidade Nova de Lisboa e o Instituto de Ciências Sociais, com o objetivo de promover o desenvolvimento da investigação em história empresarial e a cooperação entre as pessoas que trabalham nesta área de estudos.

Informações adicionais sobre o INFODOC encontram-se disponíveis em:

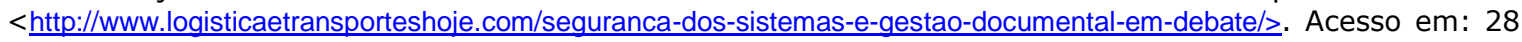
set. 2016.
} 
2). O autor confirma que a atividade desta organização coincidiu com o declínio do vigor do GTAE (BALINHA, 2012, p. 10).

No Quadro 2, e a modo de síntese, resumimos a informação considerada fundamental no que respeita aos diferentes eventos até este ponto mencionados.

Quadro 2 - Identificação dos eventos relevantes na área dos arquivos empresariais, realizados em Portugal

\begin{tabular}{|c|c|c|c|c|}
\hline Numeração & Designação & Organização & Local & Data \\
\hline$\overline{I I}$ & $\begin{array}{l}\text { Encontro de Arquivos Empresariais: } \\
\text { instrumento de gestão e património } \\
\text { documental }\end{array}$ & GTAE & Lisboa & 2000 \\
\hline I & $\begin{array}{l}\text { Encontro Internacional de Arquivos } \\
\text { Empresarias: arquivos empresariais: novos } \\
\text { desafios, novas soluções }\end{array}$ & GTAE & Lisboa & 2001 \\
\hline ॥ & $\begin{array}{l}\text { Encontro Nacional de Arquivos } \\
\text { Empresariais: gestão de arquivos } \\
\text { empresariais: experiências e projectos em } \\
\text { contexto de mudança }\end{array}$ & GTAE & Leiria & 2002 \\
\hline III & $\begin{array}{l}\text { Encontro de Arquivos Empresariais: } \\
\text { arquivos empresariais: normalização do } \\
\text { presente para a gestão do futuro }\end{array}$ & GTAE & Porto & 2004 \\
\hline I & $\begin{array}{l}\text { Conferência Internacional de Arquivos } \\
\text { Empresariais: arquivos e empresas: da } \\
\text { gestão quotidiana à memória histórica }\end{array}$ & NEHE & Famalicão & 2004 \\
\hline IV & $\begin{array}{l}\text { Encontro de Arquivos Empresariais: } \\
\text { arquivos empresariais: uma património a } \\
\text { descobrir }\end{array}$ & GTAE & Lisboa & 2005 \\
\hline I & $\begin{array}{l}\text { Congresso de Gestão Documental: Gestão } \\
\text { de Conteúdos, Workflow e Arquivo Digital }\end{array}$ & INFODOC & Lisboa & 2005 \\
\hline- & $\begin{array}{l}\text { Jornadas de outono: arquivos e gestão de } \\
\text { empresa }\end{array}$ & GTAE & Sacavém & 2006 \\
\hline II & $\begin{array}{l}\text { Congresso de Gestão Documental: } \\
\text { Workflow, Arquivo Digital, Gestão de } \\
\text { Conteúdos }\end{array}$ & INFODOC & Lisboa & 2006 \\
\hline II & $\begin{array}{l}\text { Conferência Internacional de Arquivos } \\
\text { Empresariais: fontes para a história } \\
\text { económica e social }\end{array}$ & NEHE & Seixal & 2006 \\
\hline III & $\begin{array}{l}\text { Congresso de Gestão Documental: } \\
\text { Workflow, Arquivo Digital, Gestão de } \\
\text { Conteúdos e Faturação Eletrônica }\end{array}$ & INFODOC & Lisboa & 2007 \\
\hline IV & $\begin{array}{l}\text { Congresso de Gestão Documental: Arquivo, } \\
\text { Armazenamento, Digitalização, Segurança, } \\
\text { Confidencialidade e Content Management }\end{array}$ & INFODOC & Lisboa & 2008 \\
\hline V & $\begin{array}{l}\text { Encontro de Arquivos Empresariais: } \\
\text { arquivos empresariais: assim como fizeres } \\
\text { assim acharás }\end{array}$ & GTAE & Leiria & 2015 \\
\hline VI & $\begin{array}{l}\text { Encontro de Arquivos Empresariais: } \\
\text { arquivos empresariais: quem não trabuca } \\
\text { não manduca }\end{array}$ & $\begin{array}{l}\text { GTAM e } \\
\text { GT-GDA }\end{array}$ & Oeiras & 2017 \\
\hline
\end{tabular}

O Quadro 2 mostra que, apesar da evidente relevância para a área, dos 14 eventos identificados, e que se situam num intervalo de pouco 
mais de 15 anos, apenas quatro não se realizaram na zona de influência da cidade de Lisboa, sendo de lamentar essa concentração geográfica. Outro dado a considerar, para além da periodicidade algo variável desses encontros, é a constatação da participação direta do GTAE na organização de metade desses eventos, tendo sido substituído pelo Grupo de Trabalho de Arquivos Municipais - GTAM e pelo Grupo de Trabalho de Gestão de Documentos de Arquivos - GT-GDA, a partir de 2015, após ter encerrado a sua atividade. Quanto à difusão desses eventos, conforme verificamos nas fontes consultadas, esta foi algo escassa, especialmente se considerarmos que em vários casos não foram convenientemente divulgadas as atas das quais constam os trabalhos apresentados.

\section{Tendências no uso das novas tecnologias nas empresas portuguesas}

Em Portugal, os meios utilizados para a armazenagem e a transmissão de informação nos arquivos de empresa experimentaram uma evolução semelhante àquela que se verificou em outros tipos de instituições. Os processos de automatização chegaram às organizações, a partir dos anos 80 do século XX, juntamente com a microinformática e com os novos suportes de armazenamento eletrônico e/ou digital, propiciando o que, em muitos casos, e à luz de conceitos atuais, considera-se uma manobra de reengenharia de processos, voltada para adaptar muita da documentação produzida ou acumulada pela organização a um novo espaço de gestão de informação. Claro está que estas alterações se verificaram de modos diferentes em função dos contextos.

A modernização em Portugal, tal como noutros países, em maior ou menor grau, vem associada aos imperativos e ao conjunto das inovações visionadas no âmbito da Administração Pública e, com estas, à assimilação de processos que têm lugar, fundamentalmente, no meio eletrônico. Paralelamente a essas mudanças, a atividade reguladora nessa área, que tem obedecido às diretivas europeias, vem-se realizando, desde o final da década de 80 , quando são encontrados alguns dos primeiros dispositivos jurídicos que passariam a legislar diretamente sobre estas matérias. Nos anos 90, esta atividade intensifica-se, sendo possível identificar uma maior produção de diplomas que, via de regra, legislaram sobre os seguintes aspectos: i) segurança informática e segurança de dados: Resolução do Conselho de Ministros no 5, de 1990 (PORTUGAL. Presidência do Conselho de Ministros, 1990) e Resolução do Conselho de Ministros no 16, de 1994 (PORTUGAL. Presidência do Conselho de Ministros, 1994); ii) transparência e acesso aos documentos da Administração: Lei no 65, de 1993 (PORTUGAL. Assembleia da República, 1993), Lei no 26, de 1994 (PORTUGAL. Assembleia da República, 1994), Lei no 8, de 1995 (PORTUGAL. Assembleia da República, 1995), Lei no 
104, de 1997 (PORTUGAL. Assembleia da República, 1997), Lei no 67, de 1998 (PORTUGAL. Assembleia da República, 1998), Lei no 94, de 1999 (PORTUGAL. Assembleia da República, 1999), Resolução do Conselho de Ministros no 95, de 1999 (PORTUGAL. Presidência do Conselho de Ministros, 1999), Resolução do Conselho de Ministros no 97, de 1999 (PORTUGAL. Presidência do Conselho de Ministros, 1999); iii) comércio eletrônico e iniciativa nacional para a sociedade da informação: Resolução do Conselho de Ministros no 115, de 1998 (PORTUGAL. Presidência do Conselho de Ministros, 1998), Resolução do Conselho de Ministros no 94, de 1999 (PORTUGAL. Presidência do Conselho de Ministros, 1999), Resolução do Conselho de Ministros no 96, de 1999 (PORTUGAL. Presidência do Conselho de Ministros, 1999); iv) correspondência eletrônica, documentos eletrônicos, assinatura digital e fatura eletrônica: Resolução do Conselho de Ministros no 60, de 1998 (PORTUGAL. Presidência do Conselho de Ministros, 1998), Decreto-lei no 290-D, de 1999 (PORTUGAL. Ministério da Ciência e da Tecnologia, 1999), Decretolei no 375, de 1999 (PORTUGAL. Ministério da Ciência e da Tecnologia, 1999); v) modernização administrativa e aquisição de tecnologias: Decreto-lei no 135, de 1999 (PORTUGAL. Presidência do Conselho de Ministros, 1999) e Decreto-lei no 196, de 1999 (PORTUGAL. Ministério das Finanças, 1999).

A partir da década de 2000, todo esse labor normativo não se esgota e outros dispositivos são produzidos quer como forma de alteração, revisão ou ratificação de diplomas pré-existentes, quer como nova legislação, realçando-se os que regulam: i) a iniciativa Internet e o acesso aos documentos administrativos e à sua reutilização: Resolução no 110, de 2000 (PORTUGAL. Presidência do Conselho de Ministros, 2000), Despacho no 8617, de 2002 (PORTUGAL. Ministério das Finanças, 2002), Lei no 46, de 2007 (PORTUGAL. Assembleia da República, 2007), Decretolei no 214-G, de 2015 (PORTUGAL. Ministério da Justiça, 2015); ii) as compras públicas eletrônicas: Decreto no 16, de 2000 (PORTUGAL. Ministério da Ciência e da Tecnologia, 2000), Decreto-Lei no 18, de 2008 (PORTUGAL. Ministério das Obras Públicas, Transportes e Comunicações, 2008); iii) o comércio eletrônico: Decreto-Lei no 7, de 2004 (PORTUGAL. Ministério da Justiça, 2004); iv) as assinaturas eletrônicas: Decreto-lei no 234, de 2000 (PORTUGAL. Ministério da Ciência e da Tecnologia, 2000), Decreto-Lei no 62, de 2003 (PORTUGAL. Ministério da Justiça, 2003), Decreto-Lei no 165, de 2004 (PORTUGAL. Ministério da Justiça, 2004), Decreto-Lei no 116-A, de 2006 (PORTUGAL. Presidência do Conselho de Ministros, 2006); v) o sistema de certificação eletrônica: Decreto-Lei no 116-A, de 2006 (PORTUGAL. Presidência do Conselho de Ministros, 2006); vi) as faturas eletrônicas: Decreto-Lei no 256, de 2003 (PORTUGAL. Ministério das Finanças, 2003), Resolução do Conselho de Ministros 137, de 2005 (PORTUGAL. Presidência do Conselho de Ministros 2005); vii) a privacidade nas comunicações eletrônicas: Lei no 41, de 2004 
(PORTUGAL. Assembleia da República, 2004); viii) a adoção de normas abertas, com vista à promoção da interoperabilidade dos sistemas na Administração Pública: Lei no 36, de 2011 (PORTUGAL. Assembleia da República, 2011).

Embora as leis em matéria de transparência estejam presentes em muitos países da Europa, em Portugal ainda não foi aprovado um documento desta natureza, pese embora, num passado recente, ter havido algumas tentativas. Mais recentemente, no mês de dezembro de 2011 foi apresentado ao parlamento português o projeto de lei no 115/XII (PORTUGAL. Assembleia da República, 2011), ou Lei da Transparência Ativa da Informação Pública (MIRANDA, 2015, p. 3), que ainda se encontra em fase de análise e de alterações, por parte do Parlamento.

Quanto às iniciativas que se inserem no âmbito associativo, nos últimos anos, o Grupo de Trabalho de Informação Documental (GT-ID) da Associação para a Promoção e o Desenvolvimento da Sociedade de Informação (APDSI) vem realizando alguns dos esforços mais significativos, com o intuito de conscientizar as empresas portuguesas sobre a importância da boa gestão dos recursos documentais na atual sociedade, permeada pela importância crescente atribuída à informação e ao conhecimento.

A importância que os arquivos em suporte em papel tiveram antes da expansão da informática contrasta com a que atualmente têm os suportes digitais para os processos integrais de gestão da informação. Diante desta constatação, a APDSI (2014) aborda o problema sob três perspectivas: gestão documental, gestão por processos de negócio e preservação digital.

Na perspectiva da gestão documental, os estudos da APDSI (2014) dizem-nos que a situação em Portugal está marcada por situações que sugerem ora o desconhecimento ou o descaso, ora a confusão ou o equívoco. Deste modo, os problemas diagnosticados resumem-se a cinco grupos: i) aquisição de ferramentas inadequadas; ii) elaboração de projetos focados apenas nas ferramentas; iii) escasso envolvimento dos gestores nas implementações; iv) deficiência na legislação; v) escassez de recursos humanos qualificados. No que toca ao primeiro ponto, detecta-se que, em ocasiões, o software adquirido não preenche os requisitos. No que toca ao segundo, conclui-se que há uma focalização excessiva na desmaterialização, em detrimento de outros aspectos, tais como a classificação dos documentos ou a formação profissional. No que respeita ao terceiro, verifica-se a escassa implicação dos gestores nos processos, deixando o trabalho entregue aos responsáveis pelas tecnologias. Quanto ao quarto, apontam-se situações em que o conflito entre o público e o privado é evidente, devendo ser alvo de mais reflexão e de enquadramento, dando-se como exemplos: o segredo da informação vs. o acesso aos documentos ou a digitalização de documentos classificados como secretos. Finalmente, quanto ao quinto ponto, critica-se o fato de as 
equipes informáticas assumirem tarefas de gestão documental sem possuírem competências na área (APDSI, 2014, p. 12-17).

$\mathrm{Na}$ perspectiva da aplicação do Business Process Management $B P M$, esses mesmos estudos (APDSI, 2014) ponderam que os processos de negócio executados numa organização devem ser alvo de políticas de gestão da informação. Para corroborar esta ideia, são citados alguns estudos recentes, no país, em que se realizaram diagnósticos e análises situacionais. Ditos estudos, apontados como referências na matéria, são desenvolvidos por instituições renomadas, tais como: o Instituto Português de BPM (IPBPM), a Universidade do Minho, a Associação Empresarial de Portugal e a Universidade de Utrecht, através do Observatório BPM de Portugal. Outro estudo de referência sobre o tema, e que também é mencionado pela APDSI (2014), é o inquérito por questionário realizado por Coelho (2013), constando de 37 perguntas dirigidas primeiramente às 300 maiores empresas de Portugal e, posteriormente, às Pequenas e Médias Empresas - PME e às organizações da Administração Pública ${ }^{17}$ (APDSI, 2014, p. 38).

Na perspectiva da preservação digital, que no documento em apreço (APDSI, 2014, p. 60) é definida como "a capacidade de manter, pesquisar, aceder e usar a informação digital, em todo o seu ciclo de vida e de forma colaborativa", destaca-se que, excetuando-se alguns projetos universitários alinhados com as iniciativas europeias, são escassas as empresas que apresentam soluções nesta área, em detrimento da existência de um conjunto significativo de alterações no país, nos últimos anos, que justificariam, em larga escala, a adoção de medidas sistemáticas de preservação. Entre estas alterações, podemos citar: o crescente interesse pela normalização, pela certificação e pela integração transversal dos sistemas, especialmente no âmbito fiscal; as iniciativas de desmaterialização de processos na Administração Pública, das quais são exemplos: o cartão de cidadão com certificado digital qualificado; as plataformas de compras públicas, de licenciamento e credenciação, de entrega de documentos e peças processuais nos tribunais, entre outros; as iniciativas de digitalização dos arquivos nas instituições financeiras, em substituição do microfilme e a circulação interbancária da imagem digital em detrimento dos documentos físicos; a desmaterialização de processos no setor da saúde, abrangendo atividades como consultas, internamentos,

\footnotetext{
17 A análise dos dados foi realizada usando um modelo australiano constituído por seis dimensões. Algumas das perguntas que constaram deste questionário foram as seguintes: Primeira dimensão, o alinhamento estratégico: "Os indicadores chave de desempenho (KPI) são definidos para cada processo e o desempenho de cada processo está continuamente a ser medido?". Segunda dimensão, a governação: "Para cada processo é desenvolvido um plano para determinar o orçamento, o número de pessoas e os recursos necessários, baseados na procura, meta e resultados estimados/previstos?". Terceira dimensão, os métodos: "A organização esforça-se por continuamente aperfeiçoar os processos e gerir o processo de melhoria, utilizando técnicas e o ciclo Plan, Do, Check, Act (PDCA)?". Quarta dimensão, IT: "As ferramentas de software são utilizadas para descrever e modelar os processos?". Quinta dimensão, as pessoas: "Para executar um processo de acordo com os seus objetivos, são alocadas as pessoas certas (número, conhecimento, experiência)?". Sexta dimensão, a cultura organizacional: "Dentro da organização existem comunidades formais e informais, em que os processos orientados para os funcionários (ex. donos de processos, analistas) partilham ativamente o seu conhecimento e experiência?". (APDSI, 2014, p. 38).
} 
prescrições, meios complementares de diagnóstico, processos clínicos, entre outros (APDSI, 2014, p. 78).

Dentre as iniciativas implementadas pela autoridade arquivística nacional e endossadas pelo seu superior hierárquico - a Direção-Geral do Livro, dos Arquivos e das Bibliotecas - DGLAB - são visíveis as que desenvolveram no âmbito de alguns projetos considerados estratégicos nessas matérias, entre os quais podemos citar: a Rede Portuguesa de Arquivos, $O$ Repositório de Objetos Digitais Autênticos (RODA), o Programa Administração Eletrônica e Interoperabilidade Semântica (PAEIS) e as recomendações para a produção de planos de preservação digital, vinculados à aprovação das Portarias de Gestão Documental (PGD), no âmbito da Administração Pública ${ }^{18}$.

Ainda, uma outra vertente que mais recentemente se começa a explorar é a da armazenagem de informação, pelas empresas, em sistemas de Cloud computing. Num passado não muito distante, ponderava-se sobre 0 fato de as organizações dirigem-se progressivamente para um novo contexto de trabalho que poderia denominar-se "escritório sem papeis". O uso massivo das tecnologias, segundo se previa, permitiria a recepção, a difusão e a armazenagem de documentos nato-digitais ou digitalizados, nas empresas, sob garantias de recuperação posterior ou mesmo de destruição, findos os prazos de vigência ou quando em duplicado. Esta nova forma de trabalho, favorecida pela implementação, nas empresas, de aplicações conhecidas sob o nome genérico de business intelligence, permitiria tirar partido dos dados e da informação e tomar decisões de forma rápida e eficaz.

Hoje em dia, pese embora as previsões em contrário (SELLEN; HARPER, 2002; DONALDSON, 1994), as empresas realmente dispõem de um leque amplo de informações armazenadas em diversos locais, entre os quais: os sistemas de gestão de conteúdos empresariais (ou Enterprise Content Management - ECM); os sistemas de relacionamento com os clientes (Customer Relationship Management - CRM); os sistemas de planejamento de recursos empresariais (Enterprise Resource Planning $E R P)$; os sistemas de armazenamento massivo de dados e de informação estruturada e não estruturada (e.g., correios eletrônicos, cartas, vídeos, etc.), de que são exemplo os datawarehouses.

A título ilustrativo de algumas destas tendências, elaboramos a tabela 1, que recolhe dados do uso dos serviços na nuvem para as empresas de Portugal e de alguns países, além da média da União Europeia.

Tabela 1 - Uso de serviços de cloud computing. 2014

\footnotetext{
18 Pormenores acerca destas iniciativas encontram-se disponíveis em: <http://arquivos.dglab.gov.pt/programas-e-projectos/modernizacao-administrativa/macroestruturafuncional-mef/>. Acesso em: 09 nov. 2016.
} 


\begin{tabular}{|c|c|}
\hline \multicolumn{2}{|c|}{ Uso de software Customer Relationship Management (CRM) (como um CC Service) } \\
\hline União Europeia (28) & 4 \\
\hline Portugal & 2 \\
\hline Espanha & 3 \\
\hline Finlândia & 15 \\
\hline França & 3 \\
\hline Itália & 6 \\
\hline \multicolumn{2}{|c|}{ Armazenagem de arquivos (como um CC Service) } \\
\hline União Europeia (28) & 10 \\
\hline Portugal & 6 \\
\hline Espanha & 10 \\
\hline Finlândia & 13 \\
\hline França & 7 \\
\hline Itália & 27 \\
\hline \multicolumn{2}{|c|}{ Serviços relacionados com o uso da Internet } \\
\hline União Europeia (28) & 19 \\
\hline Portugal & 13 \\
\hline Espanha & 14 \\
\hline Finlândia & 51 \\
\hline França & 12 \\
\hline Itália & 40 \\
\hline \multicolumn{2}{|c|}{ Hospedagem de bases de dados empresariais (como um $C C$ Service) } \\
\hline União Europeia (28) & 7 \\
\hline Portugal & 4 \\
\hline Espanha & 8 \\
\hline Finlândia & 19 \\
\hline França & 6 \\
\hline Itália & 11 \\
\hline
\end{tabular}

Em geral, os resultados divulgados para o ano de 2014, último de referência, demonstram um uso pouco intensivo destes serviços, incidindo a maior parte do mesmo em aplicações relacionados com a Internet e a menor parte nas demais, podendo citar como exemplos: o armazenamento de arquivos, a hospedagem de bases de dados ou o uso de softwares CRM.

\section{Conclusões}

O presente estudo pretendeu levantar conhecimentos em torno de dois eixos fundamentais: i) iniciativas internacionais e nacionais de preservação e de organização de arquivos empresariais, sobretudo no contexto europeu; ii) tendências atuais no uso das tecnologias nos arquivos empresariais portugueses. 
O levantamento das principais iniciativas internacionais leva-nos a concluir que, no passado, as iniciativas de preservação e de organização dos arquivos empresariais empreendidas pelos diversos países foram marcadas, quanto às origens, pelo caráter precoce (Alemanha, Suíça e Holanda), intermédio (Estados Unidos, França e Inglaterra) ou tardio (Itália e Espanha), verificando-se alguma tendência para a replicação de modelos. Quanto à natureza pública ou privada, algumas foram desencadeadas pelas próprias empresas, outras realizadas em parceria com instituições públicas, entre as quais se destacaram os arquivos e as universidades. Quanto aos objetivos, e de acordo com a época, foram identificados como principais: a constituição e a proteção dos arquivos; a organização e o acesso à informação. No presente, alguns dos mais importantes Arquivos Nacionais europeus e norte-americanos (Reino Unido, Estados Unidos e Canadá), e mesmo organizações de caráter associativo (Conselho Internacional de Arquivos) vêm apostando em estratégias conjuntas para os arquivos empresariais. Algumas destas iniciativas foram criticadas, no passado, por focalizar as estratégias prioritariamente no poder público e nos arquivos estatais e não nas próprias empresas.

As iniciativas nacionais identificadas no terreno jurídico revelam alguma evolução dos aspectos legislados pelos mais importantes dispositivos publicados sobre a matéria, num intervalo de quase cem anos. Conforme verificamos, a tônica atribuída, num primeiro momento, foi a patrimonialista, presente em boa parte das iniciativas empreendidas no país ao longo de quase todo o século XX. Outros dois enfoques, porém, vieram a ser acrescentados nas últimas três décadas: i) o pragmatismo, assente nas propostas de avaliação e de seleção dos documentos de empresa considerados com um elevado interesse para a memória e a história económica e social do país, bem como ii) as questões ligadas aos documentos eletrônicos gerados por estas organizações. A inclusão destas questões representou um avanço face ao conservadorismo que marcou, em essência, os dispositivos previamente publicados, embora o mesmo seja considerado insuficiente, uma vez que os dispositivos não tocam em aspectos cruciais tais como as medidas concretas de preservação a implementar no meio digital. Finalmente, de um número expressivo de diplomas identificados, são considerados relativamente poucos os que incidem diretamente na questão dos documentos de empresa, e mesmo insuficientes as matérias legisladas ou as medidas concretas de proteção e de valorização apontadas. Possivelmente, esta é uma das razões pelas quais são escassos os exemplos de iniciativas de empresas viradas para a estratégias de preservação dos seus arquivos, sublinhando-se, no entanto, na esfera pública, alguns casos pontuais de Câmaras Municipais, bem como o papel exercido pela agência nacional de arquivos e pelos arquivos distritais, tendência, aliás, que replica o que se observa no panorama internacional. 
Alguns dos importantes estudos científicos sobre o tema revelam um panorama ainda pouco animador para os arquivos de empresas em Portugal, quer pela sua função secundária, quer pela escassa sensibilidade das empresas para estas questões ou a ausência de uma tradição focada na preservação e no reconhecimento do potencial desses como fontes para a memória e a história. Por isso mesmo e segundo os mesmos estudos, esses arquivos encontram-se, em muitos casos, em risco de perda de informação, situação que tem sido repetidamente abordada nos diversos chamamentos feitos em eventos realizados no país ou mesmo pelas associações especializadas. Dentre os exemplos positivos a destacar, particularmente a partir do final dos anos 90, podemos mencionar: a APBAD, por meio do GTAE, com o projeto de sensibilização e de apoio, junto de empresários e de gestores financeiros, o estímulo ao uso de normas internacionais e a promoção de encontros e de atividades de formação sobre esses temas. A lamentar a fraca dispersão geográfica desses eventos e a pouca difusão dos seus conteúdos.

A análise das tendências atuais no uso das tecnologias em Portugal revela que, tal como noutros países, a modernização associa-se aos imperativos e às inovações voltadas para a Administração Pública, bem como à assimilação de processos derivados dos ambientes eletrônicos. A atividade reguladora nessa matéria, alinhada com as orientações europeias, vem gerando um conjunto expressivo de legislação, especialmente a partir dos anos 90 e de 2000, o que em muito se explica pelas necessidades crescentes do contexto. Dentre as matérias reguladas pelos diplomas produzidos, destacam-se, pela relação com os arquivos de empresa, os seguintes: segurança informática e de dados, transparência e acesso aos documentos, correspondência eletrônica, assinatura digital, fatura eletrônica, compras públicas eletrônicas, comércio eletrônico, sistema de certificação eletrônica, privacidade nas comunicações eletrônicas, adoção de normas abertas, com vista à promoção da interoperabilidade dos sistemas. Ainda, cumpre referir que em Portugal não foi aprovado um documento sobre a transparência da informação, 0 que se encontra em fase de análise e de alterações, desde o ano de 2011. Paralelamente a estas iniciativas, encontramos estudos relevantes, desenvolvidos sobretudo pela APDSI, dando conta da problemática da aplicação das tecnologias nas empresas portuguesas. Os resultados de um desses estudos revelaram três aspectos cruciais: i) no que toca à gestão documental, os problemas diagnosticados vão desde à aquisição até a aplicação inadequada ou ineficiente das ferramentas adquiridas; ii) no que toca à metodologia BPM, o problema mais visível é o da negligência, na sua aplicação, das políticas de gestão da informação; iii) no que toca à preservação digital, são consideradas escassas as empresas que apresentam soluções para o problema, em detrimento de já haver toda uma conjuntura favorável, aliada a uma necessidade, no país, da adoção de medidas sistemáticas para o efeito. Finalmente, em 
comparação com outros países europeus, os resultados mais recentes demonstram um uso pouco intensivo dos serviços na nuvem, em Portugal, especialmente no que se refere ao armazenamento de arquivos, à hospedagem de bases de dados ou ao uso de softwares CRM. Todas estas situações precisam ser equacionadas pelo país, de modo a que o mesmo possa figurar, num médio prazo, entre os que se beneficiam de um uso racional e inteligente das tecnologias ao serviço dos/as cidadãos/ãs.

\section{Referências}

AMATORI, F.; JONES, G. (Eds.). Business history around the world. New York: Cambridge University Press, 2003.

ANDRADE, M. D. El archivo: apoyo a la gestión y a la memoria de la empresa. Tabula: Revista de Archivos de Castilla y León, n. 8, p. 93-101, 2005.

ASSOCIAÇÃO PARA A PROMOÇÃO E DESENVOLVIMENTO DA SOCIEDADE DE INFORMAÇÃO (APDSI). Grupo de Trabalho de Informação Documental. A gestão documental na governança da informação. Lisboa: APDSI, 2014. ASSOCIAÇÃO PORTUGUESA DOS BIBLIOTECÁRIOS, ARQUIVISTAS E DOCUMENTALISTAS (APBAD). Notícia BAD. Disponível em: <http://www.bad.pt/noticia/2017/01/10/realizacao-do-6-o-encontro-dearquivos-empresariais/>. Acesso em: 9 jun. 2017.

ASSOCIAÇÃO PORTUGUESA DOS BIBLIOTECÁRIOS, ARQUIVISTAS E DOCUMENTALISTAS (APBAD). Grupo de Trabalho em Arquivos Empresariais. Arquivos empresariais: instrumentos de gestão e património documental: novos desafios, novas soluções. Lisboa: APBAD, 2001.

BALINHA, H. F. D. da. A gestão da informação nos arquivos empresariais portugueses: as instituições financeiras. 2012. 110f. Dissertação (Mestrado em Ciências da Informação e Documentação) - Universidade Nova de Lisboa, Lisboa, 2012. Disponível em: <http://run.unl.pt/handle/10362/9441>. Acesso em: 30 out. 2015.

BRASIL. Arquivo Nacional. Dicionário brasileiro de terminologia arquivística. Rio de Janeiro: Arquivo Nacional, 2005.

BRASIL. Presidência da República. Decreto no 4073, de 3 de janeiro de 2002. Regulamenta a Lei no 8.159 , de 8 de janeiro de 1991, que dispõe sobre a política nacional de arquivos públicos e privados. Diário Oficial da União, 3 jan. $2002 . \quad$ Disponível em: <http://www.planalto.gov.br/ccivil_03/decreto/2002/d4073.htm>. Acesso em: 21 set. 2017.

BRASIL. Presidência da República. Lei no 8159, de 08 de janeiro de 1991. Dispõe sobre a política nacional de arquivos públicos e privados e dá 
outras providências. Diário Oficial da União, 8 jan. 1991. Disponível em: <http://www.unesco.org/culture/natlaws/media/pdf/bresil/brazil_lei_8159 _08_01_1991_por_orof.pdf >. Acesso em: 21 set. 2017.

BRASIL. Presidência da República. Resolução n. 19, de 28 de outubro de 2003. Dispõe sobre os documentos públicos que integram o acervo das empresas em processo de desestatização e das pessoas jurídicas de direito privado sucessoras de empresas públicas. Diário Oficial da União, 28 out. 2003.2 Disponível $<$ http://pesquisa.in.gov.br/imprensa/jsp/visualiza/index.jsp?jornal=1\&pag ina $=5 \&$ data $=29 / 10 / 2003>$. Acesso em: 21 set. 2017.

COELHO, P. BPM maturity results 2013: BPM Observatory Portugal. Lisboa: Instituto Português de Business Process Management, 2013.

CORAIOLA, D. M. Relevance of business archives to the historical research on management in Brazil. Cad. EBAPE.BR, Rio de Janeiro, v. 10, n. 2, p. 254-269, jun. 2012. Disponível em: <http://www.scielo.br/scielo.php?script=sci_arttext\&pid=S1679$39512012000200002 \&$ Ing=pt\&nrm=iso >. Acesso em: 30 set. 2016.

CORDEIRO, J. M. L. Arquivos de empresa e história empresarial. In: ENCONTRO INTERNACIONAL DE ARQUIVOS EMPRESARIAIS, 1., 2001, Lisboa, Anais... Lisboa: APBAD, 2001b.

CORDEIRO, J. M. L. Uma tarefa urgente: salvar arquivos de empresa. In: ENCONTRO DE ARQUIVOS EMPRESARIAIS, 1., 2000, Lisboa, Anais... Lisboa: APBAD, 2000a.

COSTA, F. M. da. Pré-aviso sobre algumas acções cautelares no domínio da salvaguarda de arquivos históricos de origem empresarial. In: ENCONTRO DOS BIBLIOTECÁRIOS, ARQUIVISTAS E DOCUMENTALISTAS PORTUGUESES, 7., 1979, Lisboa, Anais... APBAD: Lisboa, 1979.

CRUZ, A. M.; DAMAS, C. A. Business archives in Portugal: a heritage to preserve and divulgue. Lisboa: Centro de Estudos da História do Banco Espírito Santo, 2008.

DAMAS, C. A. Arquivos históricos empresariais: um património à deriva. In: SERRÃO, J. V.; PINHEIRO; FERREIRA, F. S. M. (Orgs.). Desenvolvimento económico e mudança Social: Portugal nos últimos dois séculos. Lisboa: ISCTE, 2009. p. 663-684.

DAMAS, C. A. Patrimônio e arquivos empresariais. Arqueologia \& Indústria, n. 2-3, 1999-2000. p. 219-226.

DONALDSON, J. The use of paper versus electronic media: some considerations for the effective management of documents, records and information. South African Archives Journal, n. 36, p. 28-36, 1994. 
EUROPEAN COMISSION. European Statistics - EuroStat. Cloud computing services. Disponível em: <http://ec.europa.eu/eurostat/en/web/productsdatasets/-/ISOC_CICCE_USE>. Acesso em: 21 set. 2017.

GONZÁLEZ PEDRAZA, J. A. El patrimonio documental de la industria española. Areas: Revista Internacional de Ciencias Sociales, n. 29, p. 103111, 2010a.

GONZÁLEZ PEDRAZA, J. A. Los archivos de empresas: un estudio comparativo. Arch-e: Revista Andaluza de Archivos, n. 2, p. 31-57, 2010b.

INFANTE, M. R. El Archivero en Portugal... ¿qué le depara el futuro? Tabula: Revista de Archivos de Castilla y León, n. 8, p. 27-34, 2005.

INSTITUTO PORTUGUÊS DA QUALIDADE (IPQ). NP 4041: informação e documentação: terminologia arquivística: conceitos básicos. Caparica, 2005.

MENDES, J. A. Arquivos empresariais: história, memória e cultura de empresa. Revista Portuguesa de História, v. 35, p. 379-388, 2001-2002.

MIRANDA, E. A. C.; MUÑOZ CAÑAVATE, A. Los sitios web como servicios de información al ciudadano: un estudio sobre los 308 ayuntamientos de Portugal. Anales de Documentación, v. 18, n. 1, 2015.

NÚÑEZ FERNÁNDEZ, E. Los archivos de empresa y el patrimonio documental industrial y mercantil como patrimonio cultural. In: AUTORIA? Estudio básico sobre el patrimonio documental industrial asturiano: los archivos históricos industriales y mercantiles. Gijón: Trea, 2000. p. 99128.

OLIVEIRA, E. D. A arquivologia e os arquivos de empresas. Cadernos de Biblioteconomia, Arquivística e Documentação, v. 3, n. 3, p. 94-100, 1966.

PAULO, J. A. S. La actividad legislativa y su impacto en los archivos portugueses. Tabula: Revista de Archivos de Castilla y León, n. 8, p. 1126, 2005.

PEIXOTO, A. M. Los archivos municipales portugueses en los albores del siglo XXI. Tabula: Revista de Archivos de Castilla y León, n. 8, p. 81-92, 2005.

PORTUGAL. Assembleia da República. Lei n. 104, de 13 de setembro de 1997. Cria o Sistema de Informação para a Transparência dos Actos da Administração Pública (SITAAP) e reforça os mecanismos de transparência previstos na Lei n. 26/94, de 19 de Agosto. Diário da República, Lisboa, 13 set. 1997. Disponível em: <https://dre.pt/application/file/648788>. Acesso em: 24 set. 2016. 
PORTUGAL. Assembleia da República. Lei n. 107, de 08 de setembro de 2001. Estabelece as bases da política e do regime de protecção e valorização do património cultural. Diário da República, Lisboa, 8 set. $2001 . \quad$ Disponível em: <https://dre.pt/application/dir/pdf1sdip/2001/09/209A00/58085829.pdf> . Acesso em: 21 set. 2017.

PORTUGAL. Assembleia da República. Lei n. 13, de 16 de julho de 1985. Património cultural português. Diário da República, Lisboa, 16 jul. 1985. Disponível em: <https://dre.pt/pdf1s/1985/07/15300/18651874.pdf>. Acesso em: 20 set. 2017.

PORTUGAL. Assembleia da República. Lei n. 26, de 19 de agosto de 1994. Regulamenta a obrigatoriedade de publicitação dos benefícios concedidos pela Administração Pública a particulares. Diário da República, Lisboa, 19 ago. 1994. Disponível em: <https://dre.pt/application/file/218441>. Acesso em: 21 set. 2017.

PORTUGAL. Assembleia da República. Lei n. 36, de 21 de junho de 2011. Estabelece a adopção de normas abertas para a informação em suporte digital na Administração Pública, promovendo a liberdade tecnológica dos cidadãos e organizações e a interoperabilidade dos sistemas informáticos do Estado. Diário da República, Lisboa, 21 jun. 2011. Disponível em: <https://dre.pt/application/file/670380>. Acesso em: 21 set. 2017.

PORTUGAL. Assembleia da República. Lei n. 41, de 18 de agosto de 2004. Transpõe para a ordem jurídica nacional a Directiva n. ${ }^{\circ}$ 2002/58/CE, do Parlamento Europeu e do Conselho, de 12 de Julho, relativa ao tratamento de dados pessoais e à protecção da privacidade no sector das comunicações electrónicas. Diário da República, Lisboa, 18 ago. 2004. Disponível em: $<$ http://www.dre.pt/pdf1s/2004/08/194A00/52415245.pdf $>$. Acesso em: 21 set. 2017.

PORTUGAL. Assembleia da República. Lei n. 46, de 05 de julho de 2007. Estabelece os princípios e as regras do intercâmbio transfronteiriço de informações relativas ao registo de veículos, para efeitos de prevenção e investigação de infrações penais, adaptando a ordem jurídica interna às Decisões 2008/615/JAI e 2008/616/JAI. Diário da República, Lisboa, 05 jul. 2007. Disponível em: <https://dre.tretas.org/pdfs/2017/07/05/dre3019638.pdf>. Acesso em: 21 set. 2017.

PORTUGAL. Assembleia da República. Lei n. 65, de 26 de agosto de 1993. Acesso aos documentos da Administração. Diário da República, Lisboa, 26 ago. 1993. Disponível em: <https://dre.pt/application/file/632316>. Acesso em: 21 set. 2017.

PORTUGAL. Assembleia da República. Lei n. 67, de 26 de outubro de 1998. Transpõe para a ordem jurídica interna a Directiva no 95/46/CE 
(EUR-Lex), do Parlamento Europeu e do Conselho, de 24 de Outubro de 1995, relativa à protecção das pessoas singulares no que diz respeito ao tratamento de dados pessoais e à livre circulação desses dados. Lei da Proteç̧ão de Dados Pessoais. Diário da República, Lisboa, 26 out. 1998. Disponível em: <https://dre.pt/application/file/239889>. Acesso em: 21 set. 2017.

PORTUGAL. Assembleia da República. Lei n. 8, de 29 de março de 1995. Regulamenta os serviços de apoio à Comissão de Acesso aos Documentos Administrativos e clarifica aspectos da disciplina do acesso aos documentos da Administração Pública. Diário da República, Lisboa, 29 mar. 1995. Disponível em: <https://dre.pt/application/file/173647>. Acesso em: 21 set. 2017.

PORTUGAL. Assembleia da República. Lei n. 94, de 16 de julho de 1999. Segunda alteração à Lei n. 65/93, de 26 de agosto, alterada pela Lei $n^{\circ}$ 8/95, de 29 de março, que regula o acesso aos documentos da Administração. Diário da República, Lisboa, 16 jul. 1999. Disponível em: <https://dre.pt/application/file/356629 >. Acesso em: 21 set. 2017.

PORTUGAL. Assembleia da República. Projeto de Lei n. 115/XII. Lei da Transparência Activa da Informação Pública: iniciativa. Disponível em: $<$ https://www.parlamento.pt/ActividadeParlamentar/Paginas/DetalheInicia tiva.aspx?BID=36608>. Acesso em: 21 set. 2017.

PORTUGAL. Código Commercial, de 6 de setembro de 1888. Livro Primeiro. Do commercio em geral. Diário do Governo, Lisboa, 6 set. 1888. Disponível em: <http://www.dgpj.mj.pt/sections/leis-da-justica/pdfult/sections/leis-da-justica/pdf-ult/codi-comercial-de1888/downloadFile/file/CodComercial.pdf?nocache $=1188821262.8>$. Acesso em: 20 set. 2017.

PORTUGAL. Ministério das Finanças. Portaria n. 703, de 25 de novembro de 1976. Determina os prazos de conservação e arquivo dos documentos na posse de empresas públicas. Diário da República, Lisboa, 25 nov. 1976. Disponível em: <https://dre.pt/pdf1s/1976/11/27600/26362636.pdf>. Acesso em: 20 set. 2017.

PORTUGAL. Direç̧ão-Geral do Livro, dos Arquivos e das Bibliotecas. Presidência do Conselho de Ministros. Despacho n. 9339, de 11 de julho de 2012. Cria as unidades orgânicas flexíveis da Direção-Geral do Livro, dos Arquivos e das Bibliotecas. Diário da República, Lisboa, 11 jul. 2012. Disponível em: <https://dre.tretas.org/pdfs/2012/07/11/dre302295.pdf>. Acesso em: 21 set. 2017.

PORTUGAL. Ministério da Ciência e da Tecnologia. Decreto-lei n. 375, de 18 de setembro de 1999. Estabelece a equiparação entre a factura emitida em suporte papel e a factura electrónica. Diário da República, Lisboa, 18 
set. 1999. Disponível em: <http://data.dre.pt/eli/declei/375/1999/09/18/p/dre/pt/html>. Acesso em: 21 set. 2017.

PORTUGAL. Ministério da Ciência e da Tecnologia. Decreto n. 16, de 02 de outubro de 2000. Regulamenta o Decreto-Lei n.o 375/99, de 18 de Setembro, que estabelece a equiparação entre fatura emitida em suporte de papel e a fatura eletrónica. Diário da República, Lisboa, 02 out. 2000. Disponível em: <https://dre.pt/pdf1s/2000/10/228B00/54085410.pdf>. Acesso em: 20 set. 2017.

PORTUGAL. Ministério da Ciência e da Tecnologia. Decreto-lei n. 234, de 25 de setembro de 2000. Cria o Conselho Técnico de Credenciação como estrutura de apoio ao Instituto das Tecnologias da Informação na Justiça no exercício das funções de autoridade credenciadora de entidades certificadoras de assinaturas digitais. Diário da República, Lisboa, 25 set. $2000 . \quad$ Disponível em: <https://dre.pt/pdf1s/2000/09/222A00/51315131.pdf>. Acesso em: 21 set. 2017.

PORTUGAL. Ministério da Ciência e da Tecnologia. Decreto-lei n. 290-d, de 02 de agosto de 1999. Aprova o regime jurídico dos documentos electrónicos e da assinatura digital. Diário da República, Lisboa, 02 ago. 1999. Disponível em: <https://dre.pt/web/guest/pesquisa/Lsearch/445741/details/maximized>. Acesso em: 21 set. 2017.

PORTUGAL. Ministério da Cultura e Coordenação Científica. Decreto-lei n. 149, de 05 de abril de 1983. Define o regime jurídico dos arquivos distritais e das bibliotecas públicas. Diário da República, Lisboa, 05 abr. 1983. Disponível em: <https://dre.pt/application/file/a/312358>. Acesso em: 20 set. 2017.

PORTUGAL. Ministério da Cultura. Decreto-lei n. 206, de 26 de junho de 1985. Dá nova redacção ao artigo $10{ }^{\circ}$ do Decreto-Lei n. ${ }^{\circ} 149 / 83$, de 5 de Abril, que define o regime jurídico dos arquivos distritais e das bibliotecas públicas. Diário da República, Lisboa, 26 jun. 1985. Disponível em: <http://www.uc.pt/auc/instituicao/DL 206-85>. Acesso em: 17 set. 2017.

PORTUGAL. Ministério da Cultura. Decreto-lei n. 248, de 08 de outubro de 2003. Altera o Decreto-Lei n. ${ }^{149 / 83}$, de 5 de Abril, que define o regime jurídico dos arquivos distritais e das bibliotecas públicas, no concernente ao preço dos bens e serviços prestados. Diário da República, Lisboa, 08 out. 2003. Disponível em: <https://dre.pt/application/file/482515>. Acesso em: 7 set. 2016.

PORTUGAL. Ministério da Cultura. Decreto-Lei n. 372, de 23 de novembro de 1998. Aprova a Lei Orgânica do Conselho Superior de Arquivos. Diário da República, Lisboa, 23 nov. 1998. Disponível em: 

em: 21 set. 2017.

PORTUGAL. Ministério da Cultura. Decreto-Lei n. 60, de 20 de março de 1997. Aprova a orgânica do Instituto dos Arquivos Nacionais/Torre do Tombo, do Ministério da Cultura. Diário da República, Lisboa, 20 mar. 1997. Disponível em: <http://data.dre.pt/eli/declei/60/1997/03/20/p/dre/pt/html>. Acesso em: 21 set. 2017.

PORTUGAL. Ministério da Cultura. Direção-Geral do Livro, dos Arquivos e das Bibliotecas. O Arquivo Nacional da Torre do Tombo: história. Disponível em: <http://antt.dglab.gov.pt/inicio/identificacaoinstitucional/6-2/>. Acesso em: 26 set. 2016.

PORTUGAL. Ministério da Justiça. Decreto-Lei n. 165, de 06 de julho de 2004. Altera o artigo 29.0 do Decreto-Lei n. 290-D/99, de 2 de agosto, que aprova o regime jurídico dos documentos eletrónicos e da assinatura digital, na redação que Ihe foi dada pelo Decreto-Lei n.0 62/2003, de 3 de abril. Diário da República, Lisboa, 06 jul. 2004. Disponível em: <https://dre.pt/pdf1s/2004/07/157A00/40724073.pdf $>$. Acesso em: 20 set. 2017.

PORTUGAL. Ministério da Justiça. Decreto-lei n. 214-g, de 02 de outubro de 2015. No uso da autorização legislativa concedida pela Lei n.o 100/2015, de 19 de agosto, revê o Código de Processo nos Tribunais Administrativos, o Estatuto dos Tribunais Administrativos e Fiscais, o Código dos Contratos Públicos, o Regime Jurídico da Urbanização e da Edificação, a Lei de Participação Procedimental e de Ação Popular, o Regime Jurídico da Tutela Administrativa, a Lei de Acesso aos Documentos Administrativos e a Lei de Acesso à Informação sobre Ambiente. Diário da República, Lisboa, 02 out. 2015. Disponível em: <https://dre.pt/application/file/70441118>. Acesso em: 21 set. 2017.

PORTUGAL. Ministério da Justiça. Decreto-Lei n. 41, de 04 de fevereiro de 1972. Dá nova redacção ao artigo $400^{\circ}$ do Código Comercial. Diário da República, Lisboa, 04 fev. 1972. Disponível em: $<$ https://dre.pt/web/quest/pesquisa//search/398370/details/normal?q=Decreto-Lei+n.+41, 1972. $>$. Acesso em: 21 set. 2017.

PORTUGAL. Ministério da Justiça. Decreto-Lei n. 62, de 02 de agosto de 2003. Altera o Decreto-Lei n. 290-D/99, de 2 de agosto, que aprova o regime jurídico dos documentos electrónicos e da assinatura digital. Diário da República, Lisboa, 02 ago. 2003. Disponível em: $<$ http://data.dre.pt/eli/dec-lei/62/2003/04/03/p/dre/pt/html>. Acesso em: 21 set. 2017.

PORTUGAL. Ministério da Justiça. Decreto-Lei n. 7, de 07 de janeiro de 2004. No uso da autorização legislativa concedida pela Lei n. $7 / 2003$, de 9 
de maio, transpõe para a ordem jurídica nacional a Directiva n. 2000/31/CE, do Parlamento Europeu e do Conselho, de 8 de Junho de 2000, relativa a certos aspectos legais dos serviços da sociedade de informação, em especial do comércio electrónico, no mercado interno. Diário da República, Lisboa, 07 jan. 2004. Disponível em: $<$ http://data.dre.pt/eli/dec-lei/7/2004/01/07/p/dre/pt/html>. Acesso em: 21 set. 2017.

PORTUGAL. Ministério das Finanças. Decreto-lei n. 196, de 08 de junho de 1999. Fixa as regras relativas à coordenação da aquisição e utilização de tecnologias de informação na Administração Pública e estabelece regras específicas para a locação, sob qualquer regime, ou a aquisição de bens ou serviços de informática. Diário da República, Lisboa, 08 jun. 1999. Disponível em: <https://dre.tretas.org/pdfs/1999/06/08/plain103083.pdf>. Acesso em: 20 set. 2017.

PORTUGAL. Ministério das Finanças. Decreto-Lei n. 256, de 21 de outubro de 2003. Transpõe para a ordem jurídica nacional a Diretiva $n$. 2001/115/CE, do Conselho, de 20 de Dezembro, que altera a Diretiva n. $77 / 388 / C E E$, tendo em vista simplificar, modernizar e harmonizar as condições aplicáveis à faturação em matéria de imposto sobre o valor acrescentado. Diário da República, Lisboa, 21 out. 2003. Disponível em: $<$ https://dre.pt/pdf1s/2003/10/244A00/70247027.pdf>. Acesso em: 21 set. 2017.

PORTUGAL. Ministério das Finanças. Despacho n. 8617, de 29 de abril de 2002. Fixa os preços dos documentos administrativos, através de fotocópias, ou qualquer outro meio técnico de reprodução, a suportar pelos cidadãos. Diário da República, Lisboa, 29 abr. 2002. Disponível em: $<$ https://dre.tretas.org/pdfs/2002/04/29/dre-151644.pdf $>$. Acesso em: 21 set. 2017.

PORTUGAL. Ministério das Finanças. Ministério da Administração Pública. Ministério da Justiça. Decreto-lei n. 76-a, de 29 de março de 2006. Actualiza e flexibiliza os modelos de governo das sociedades anónimas, adopta medidas de simplificação e eliminação de actos e procedimentos notariais e registrais e aprova o novo regime jurídico da dissolução e da liquidação de entidades comerciais. Diário da República, Lisboa, 29 mar. $2006 . \quad$ Disponível em: <http://www.umic.pt/images/stories/publicacoes/DL 76A 2006.pdf $>$. Acesso em: 21 set. 2017.

PORTUGAL. Ministério das Finanças. Ministério da Cultura. Despacho Conjunto n. 427, de 20 de maio de 1999. Cria um Grupo de Trabalho que terá as seguintes atribuições [...]. Diário da República, Lisboa, 20 maio 1999. Disponível em: <https://dre.tretas.org/dre/102659/despachoconjunto-427-99-de-20-de-maio - in links >. Acesso em: 21 set. 2017. 
PORTUGAL. Ministério das Obras Públicas, Transportes e Comunicações. Decreto-Lei n. 18, de 29 de janeiro de 2008. Aprova o Código dos Contratos Públicos, que estabelece a disciplina aplicável à contratação pública e o regime substantivo dos contratos públicos que revistam a natureza de contrato administrativo. Diário da República, Lisboa, 29 jan. 2008. Disponível

em: $<$ https://dre.pt/pdf1s/2008/01/02000/0075300852.pdf>. Acesso em: 20 set. 2017.

PORTUGAL. Presidência do Conselho de Ministros. Decreto-Lei n. 103, de 16 de maio de 2012. Aprova a orgânica da Direção-Geral do Livro, dos Arquivos e das Bibliotecas (DGLAB). Diário da República, Lisboa, 16 maio 2012. Disponível em: <https://dre.pt/pdf1s/2012/05/09500/0253502537.pdf>. Acesso em: 20 set. 2017.

PORTUGAL. Presidência do Conselho de Ministros. Decreto-Lei n. 116-a, de 16 de junho de 2006. Procede à criação do Sistema de Certificação Eletrónica do Estado - Infraestrutura de Chaves Públicas e designa a Autoridade Nacional de Segurança como autoridade credenciadora nacional. Diário da República, Lisboa, 16 jun. 2006. Disponível em: $<$ https://dre.pt/pdf1s/2006/06/115A02/00040008.pdf>. Acesso em: 20 set. 2017.

PORTUGAL. Presidência do Conselho de Ministros. Decreto-lei n. 121, de 02 de julho de 1992. Estabelece os princípios de gestão de documentos relativos a recursos humanos, recursos financeiros e recursos patrimoniais dos serviços da administração direta e indireta do Estado Diário da República, Lisboa, 02 jul. 1992. Disponível em: <https://dre.pt/application/dir/pdf1sdip/1992/07/150A00/31463147.pdf> . Acesso em: 20 set. 2017.

PORTUGAL. Presidência do Conselho de Ministros. Decreto-lei n. 135, de 22 de abril de 1999. Estabelece medidas de modernização administrativa a que devem obedecer os serviços e organismos da Administração Pública na sua actuação face ao cidadão, designadamente sobre acolhimento e atendimento dos cidadãos em geral e dos agentes económicos em particular, comunicação administrativa, simplificação de procedimentos, audição dos utentes e sistema de informação para a gestão. Diário da República, Lisboa, 22 abr. 1999. Disponível em: <https://dre.pt/application/file/534675>. Acesso em: 20 set. 2017.

PORTUGAL. Presidência do Conselho de Ministros. Decreto-Lei n. 152, de 29 de abril de 1988. Cria o Instituto Português de Arquivos (IPA). Diário da República, Lisboa, 29 abr. 1988. Disponível em: <https://dre.pt/application/file/285386 >. Acesso em: 20 set. 2017.

PORTUGAL. Presidência do Conselho de Ministros. Decreto-Lei n. 447, de 10 de dezembro de 1988. Regula a pré-arquivagem de documentação. 
Diário da República, Lisboa, 10 dez. 1988. Disponível em: $<$ https://dre.pt/pdf1s/1988/12/28400/48854885.pdf>. Acesso em: 20 set. 2017.

PORTUGAL. Presidência do Conselho de Ministros. Ministério das Finanças. Portaria n. 192, de 19 de junho de 2012. Fixa a estrutura nuclear da Direção-Geral do Livro, dos Arquivos e das Bibliotecas. Diário da República, Lisboa, 19 jun. 2012. Disponível em: <https://dre.pt/application/file/178885 >. Acesso em: 21 set. 2017.

PORTUGAL. Presidência do Conselho de Ministros. Resolução do Conselho de Ministros n. 110, de 08 de agosto de 2000. Aprova e publica em anexo os Estatutos do Instituto de Gestão do Crédito Público (IGCP). Diário da República, Lisboa, 08 ago. 2000. Disponível em: <https://dre.pt/application/file/2585942>. Acesso em: 24 set. 2016.

PORTUGAL. Presidência do Conselho de Ministros. Resolução do Conselho de Ministros n. 115, de 01 de setembro de 1998. Cria a Iniciativa Nacional para o Comércio Electrónico e define os seus objectivos. Diário da República, Lisboa, 01 set. 1998. Disponível em: <https://dre.pt/application/file/566572>. Acesso em: 21 set. 2017.

PORTUGAL. Presidência do Conselho de Ministros. Resolução do Conselho de Ministros n. 137, de 17 de agosto de 2005. Transpõe para a ordem jurídica nacional a Directiva n. 2001/115/CE (EUR-Lex), do Conselho, de 20 de Dezembro, que altera a Directiva n. 77/388/CEE (EUR-Lex), tendo em vista simplificar, modernizar e harmonizar as condições aplicáveis à facturação em matéria de imposto sobre o valor acrescentado. Diário da República, Lisboa, 17 ago. 2005. Disponível em: <https://dre.pt/application/file/243380 >. Acesso em: 21 set. 2017.

PORTUGAL. Presidência do Conselho de Ministros. Resolução do Conselho de Ministros n. 16, de 22 de março de 1994. Aprova as instruções para a segurança das telecomunicações (SEGNAC 3). Diário da República, Lisboa, 22 mar. $1994 . \quad$ Disponível em: <http://www.cfsirp.pt/images/legislacao/segnac3.pdf >. Acesso em: 21 set. 2017.

PORTUGAL. Presidência do Conselho de Ministros. Resolução do Conselho de Ministros n. 5, de 28 de fevereiro de 1990. Aprova as instruções sobre a segurança informática (SEGNAC 4). Diário da República, Lisboa, 28 fev. 1990. Disponível em: <http://www.cfsirp.pt/images/legislacao/segnac4.pdf >. Acesso em: 21 set. 2017.

PORTUGAL. Presidência do Conselho de Ministros. Resolução do Conselho de Ministros n. 60, de 06 de maio de 1998. Determina a existência de um endereço de correio electrónico nos serviços e organismos integrados na administração directa e indirecta do Estado e regula o valor a atribuir à 
correspondência transmitida por via electrónica. Diário da República, Lisboa, 06 maio $1998 . \quad$ Disponível em: <https://dre.pt/application/file/516849 >. Acesso em: 21 set. 2017.

PORTUGAL. Presidência do Conselho de Ministros. Resolução do Conselho de Ministros n. 94, de 25 de agosto de 1999. Aprova o Documento Orientador da Iniciativa Nacional para o Comércio Electrónico. Diário da República, Lisboa, 25 ago. 1999. Disponível em: <https://dre.pt/application/dir/pdf1sdip/1999/08/198B00/57535762.pdf> . Acesso em: 21 set. 2017.

PORTUGAL. Presidência do Conselho de Ministros. Resolução do Conselho de Ministros n. 95, de 25 de agosto de 1999. Determina a disponibilização na Internet de informação detida pela Administração Pública. Diário da República, Lisboa, 25 ago. 1999. Disponível em: <https://dre.pt/application/dir/pdf1sdip/1999/08/198B00/57635764.pdf> . Acesso em: 21 set. 2017.

PORTUGAL. Presidência do Conselho de Ministros. Resolução do Conselho de Ministros n. 96, de 26 de agosto de 1999. Cria a Iniciativa Nacional para os Cidadãos com Necessidades Especiais na Sociedade da Informação e aprova o respectivo documento orientador. Diário da República, Lisboa, 26 ago. 1999. Disponível em: <https://dre.pt/application/dir/pdf1s/1999/08/199B00/58225829.pdf>. Acesso em: 21 set. 2017.

PORTUGAL. Presidência do Conselho de Ministros. Resolução do Conselho de Ministros n. 97, de 26 de agosto de 1999. Estabelece regras relativas à acessibilidade pelos cidadãos com necessidades especiais aos conteúdos de organismos públicos na Internet. Diário da República, Lisboa, 26 ago. 1999. Disponível em: $<$ https://www.consumidor.gov.pt/wwwbase/acessibilidade/ResConsMin 9 7 99.pdf >. Acesso em: 21 set. 2017.

PORTUGAL. Presidência do Conselho. Secretaria-Geral. Decreto-lei n. 29, de 24 de janeiro de 1972. Torna extensivo à generalidade dos serviços de natureza pública, estabelecendo as normas para a sua uniformização, o uso da microfilmagem dos documentos em arquivo, com a consequente inutilização dos respectivos originais. Diário da República, Lisboa, 24 jan. 1972. Disponível em: <https://dre.pt/web/guest/pesquisa//search/400002/details/normal?q=decreto-lei+no 29+1972>. Acesso em: 21 set. 2017.

PORTUGAL. Secretaria de Estado da Cultura. Decreto-lei n. 429, de 15 de outubro de 1977. Estabelece normas relativas à salvaguarda de arquivos e bens culturais pertencentes a empresas privadas. Diário da República, Lisboa, 15 out. $1977 . \quad$ Disponível em: <https://dre.pt/application/file/279282 >. Acesso em: 21 set. 2017. 
RIDER, P. E. Business archives notes. Archivaria, v. 1, n. 1, p. 93-94, winter 1975-1976.

RODRIGUES, M. F. Arquivos das empresas: património ignorado. Estudos Aveirenses, n. 1, p. 151-163, 1993.

RODRIGUES, M. F. Da necessidade de preservação dos arquivos das empresas e do seu valor para a história local. In: ENCONTRO DE HISTÓRIA LOCAL DE ESPINHO, 1., 1995, Espinho, Anais... Câmara Municipal: Espinho, 1995.

SELLEN, A. J., HARPER, R. H. R. The myth of the paperless office. Cambridge: The MIT Press, 2002.

SENÉCAL, S. Archives historiques et organisation: une difficile rencontre. Archives, v. 45, n. 1, p. 201-214, 2013.

SILVA, A. B. M. da. Defesa e estudo dos arquivos empresariais: algumas notas para um plano de actuação urgente. In: ENCONTRO NACIONAL SOBRE O PATRIMÓNIO INDUSTRIAL, 1., 1986, Anais... Coimbra: Coimbra, 1989.

SOUSA, A. F. de. 90 años: los archivos de distrito en Portugal. Tabula: Revista de Archivos de Castilla y León, n. 8, p. 69-80, 2005.

TOUSEY, B. H.; ADKINS, E. W. Access to business archives: U.S. access philosophies. In: JAPAN-U.S. ARCHIVES SEMINAR, 2007. Anais eletrônicos... Tokyo: Japan-U.S. Archives Seminar Executive Committee, Society of American Archivists, 2007. Disponível em: <http://www.archivists.org/publications/proceedings/accesstoarchives/>. Acesso em: 30 set. 2016. 